\title{
Status of Marine Biodiversity in the Anthropocene
}

\author{
Thomas Luypaert, James G. Hagan, Morgan L. McCarthy, \\ and Meenakshi Poti
}

\begin{abstract}
Marine biodiversity plays an important role in providing the ecosystem functions and services which humans derive from the oceans. Understanding how this provisioning will change in the Anthropocene requires knowledge of marine biodiversity patterns. Here, we review the status of marine species diversity in space and time. Knowledge of marine species diversity is incomplete, with only $11 \%$ of species described. Nonetheless, marine biodiversity is clearly under threat, and habitat destruction and overexploitation represent the greatest stressors to threatened marine species. Claims that global marine extinction rates are within historical backgrounds and lower than on land may be inaccurate, as fewer marine species have been assessed for extinction risk. Moreover,
\end{abstract}

extinctions and declines in species richness at any spatial scale may inadequately reflect marine diversity trends. Marine local-scale species richness is seemingly not decreasing through time. There are, however, directional changes in species composition at local scales. These changes are non-random, as resident species are replaced by invaders, which may reduce diversity in space and, thus, reduce regional species richness. However, this is infrequently quantified in the marine realm and the consequences for ecosystem processes are poorly known. While these changes in species richness are important, they do not fully reflect humanity's impact on the marine realm. Marine population declines are ubiquitous, yet the consequences for the functioning of marine ecosystems are understudied. We call for increased emphasis on trends in

T. Luypaert $(\bowtie)$

Faculty of Sciences and Bioengineering Sciences, Department of Biology, Vrije Universiteit Brussel (VUB), Brussels, Belgium

Faculty of Sciences, Department of Biology of Organisms, Université libre de Bruxelles (ULB), Brussels, Belgium

Faculty of Maths, Physics and Natural Sciences, Department of Biology, Università degli Studi di Firenze (UniFi),

Sesto Fiorentino, Italy

J. G. Hagan

Faculty of Sciences and Bioengineering Sciences, Department of Biology, Vrije Universiteit Brussel (VUB), Brussels, Belgium

Faculty of Sciences, Department of Biology of Organisms, Université libre de Bruxelles (ULB), Brussels, Belgium

M. L. McCarthy

Faculty of Sciences and Bioengineering Sciences, Department of Biology, Vrije Universiteit Brussel (VUB), Brussels, Belgium

Faculty of Sciences, Department of Biology of Organisms, Université libre de Bruxelles (ULB), Brussels, Belgium

Faculty of Maths, Physics and Natural Sciences, Department of Biology, Università degli Studi di Firenze (UniFi),

Sesto Fiorentino, Italy

School of Biological Sciences, The University of Queensland (UQ), St. Lucia, Queensland, Australia

M. Poti

Faculty of Sciences and Bioengineering Sciences, Department of Biology, Vrije Universiteit Brussel (VUB), Brussels, Belgium

Faculty of Sciences, Department of Biology of Organisms, Université libre de Bruxelles (ULB), Brussels, Belgium

Faculty of Maths, Physics and Natural Sciences, Department of Biology, Università degli Studi di Firenze (UniFi),

Sesto Fiorentino, Italy

School of Marine and Environmental Sciences, University of Malaysia Terengganu (UMT),

Terengganu, Kuala Terengganu, Malaysia

Sea Turtle Research Unit (SEATRU), Institute of Oceanography and Environment, Universiti Malaysia Terengganu (UMT), Kuala Terengganu, Malaysia 
abundance, population sizes and biomass of marine species to fully characterize the pervasiveness of anthropogenic impacts on the marine realm.

\section{Keywords}

Extinction - Defaunation · Biotic homogenization · Conservation · Anthropogenic stressors · Ecosystem function $\cdot$ Ecosystem service $\cdot$ Marine threats

\subsection{Introduction}

Humans have impacted $87-90 \%$ of the global ocean surface (Halpern et al. 2015; Jones et al. 2018). Marine fish abundance has declined by $38 \%$ compared to levels in 1970 (Hutchings et al. 2010). The area of certain coastal marine habitats, like seagrass beds and mangroves, has been depleted by over two-thirds (Lotze et al. 2006). Anthropogenic activities have increased atmospheric carbon dioxide $\left(\mathrm{CO}_{2}\right)$ concentrations by over $40 \%$ relative to pre-industrial levels (Caldeira and Wickett 2003), reducing the global ocean $\mathrm{pH}$ by 0.1 unit in the past century (Orr et al. 2005). The scale of these human impacts has triggered the naming of a new geological epoch, the Anthropocene, where humans dominate biogeochemical cycles, net primary production, and alter patterns of biodiversity in space and time (Crutzen 2002; Haberl et al. 2007). These impacts have led to a loss of global biodiversity which is comparable to previous global-scale mass extinction events (see Box 4.1; Barnosky et al. 2011; Ceballos et al. 2015), suggesting that we are in a biodiversity crisis.

Addressing this human-induced biodiversity crisis is one of the most challenging tasks of our time (Steffen et al. 2015). The conservation of biodiversity is an internationally accepted goal, as exemplified by the United Nations Convention on Biological Diversity (CBD) Strategic Plan for Biodiversity 2011-2020, which aims to "take effective and urgent action to halt the loss of biodiversity in order to ensure that by 2020 ecosystems are resilient and continue to provide essential services" (CBD COP Decision X/2 2010). Furthermore, international policies with marine biodiversity targets are being adapted at national and regional levels (Lawler et al. 2006), as is reflected by the recent addition of Sustainable Development Goal 14: "Conserve and sustainably use the ocean, seas and marine resources" (United Nations General Assembly 2015). These goals focus on a multi-level concept of biodiversity: biological variation in all its manifestations from genes, populations, species, and functional traits to ecosystems (Gaston 2010).

The wide acceptance of these national and international policy goals reflects a growing understanding of the importance of biodiversity to humans (Costanza et al. 1997; Palumbi et al. 2009; Barbier et al. 2011). Marine ecosystems provide a variety of benefits to humanity. These ecosystem services (see Box 4.1) include the supply of over a billion people with their primary protein source, widespread waste processing, shoreline protection, recreational opportunities, and many others (MEA 2005; Worm et al. 2006; Palumbi et al. 2009). However, as marine ecosystems are degraded and biodiversity declines, the ability of ecosystems to deliver these ecosystem services is being lost (MEA 2005). Moreover, pressures on the marine realm may increase if the terrestrial environment continues to be degraded and humankind becomes increasingly reliant on marine ecosystem services (McCauley et al. 2015).

The provisioning of ecosystem services is strongly coupled to ecosystem functioning (Cardinale et al. 2012; Harrison et al. 2014). Ecosystem functions (see Box 4.1) refer broadly to processes that control fluxes of energy and material in the biosphere and include nutrient cycling, primary productivity, and several others. There is now unequivocal evidence that high biodiversity within biological communities enhances ecosystem functioning in a variety of marine ecosystems and taxonomic groups (reviewed in Palumbi et al. 2009; Cardinale et al. 2012; Gamfeldt et al. 2015). These studies mostly focus on local-scale diversity and on productivity as the ecosystem function. Nonetheless, similar patterns have been found at larger spatial scales (Worm et al. 2006) and for various other ecosystem functions (Lefcheck et al. 2015). Marine biodiversity is also linked to ecosystem stability through time (see Box 4.1; McCann 2000; Schindler et al. 2015). High fish diversity, for example, is associated with fisheries catch stability through time (Greene et al. 2010). Thus, diversity is not only linked to ecosystem functioning in marine communities but also improves the stability of these functions through time.

Several mechanisms have been proposed to explain the link between biodiversity, and ecosystem functioning and stability. For example, species occupying different niches is known as complementarity. "Complementarity effects" appear prevalent in marine ecosystems as niche partitioning is commonly documented (Ross 1986; Garrison and Link 2000). Diverse assemblages of herbivorous fishes on coral reefs, for instance, are more efficient at grazing macroalgae due to different feeding strategies (Burkepile and Hay 2008). Furthermore, diverse communities are also more likely to contain well-adapted species, or species which disproportionately affect ecosystem function (Palumbi et al. 2009). These "selection effects" can be important, as single species can have strong effects on ecosystem functions in marine systems (Paine 1969; Mills et al. 1993; Gamfeldt et al. 2015). The evidence for complementarity and selection effects suggests that the mechanisms driving the effect of diversity on ecosystem functioning are linked to functional diversity (see Box 4.1) — or the range of functions that organisms perform in an ecological community (Petchey and Gaston 2006). However, several species from the same functional group can be important for maintaining the stability of an ecosystem over time as species often respond differentially to temporal environmen- 


\section{Box 4.1 Glossary}

\section{Ecosystem-related terms}

Ecosystem engineers: Species that regulate resource availability to other species by altering biotic or abiotic materials (Jones et al. 1994).

Ecosystem services: The benefits that humans derive from ecosystems (Cardinale et al. 2012).

Ecosystem function: Any ecological process that affects the fluxes of organic matter, nutrients and energy (Cardinale et al. 2012).

Ecosystem stability: The variability in an ecosystem property (e.g., biomass, species richness, primary productivity) through time (Schindler et al. 2015). Stable communities are those with low variability in ecosystem properties through time.

Keystone species: Species that affect communities and ecosystems more strongly than predicted from their abundance (Power et al. 1996).

\section{Extinction and defaunation terms}

Background extinction: The rate of natural species extinction through time prior to the influence of humans (Pimm et al. 1995).

Extinctions per million species years (E MSY-1): The metric used to measure background extinction rates. This metric measures the number of extinctions per million species years. For example, if there are 20 million species and an extinction rate of $1 \mathrm{E} \mathrm{MSY}^{-1}, 20$ species would be predicted to go extinct each year.

Mass extinction event: Substantial biodiversity losses that are global in extent, taxonomically broad, and rapid relative to the average duration of existence for the taxa involved (Jablonski 1986). The 'Big Five' are quantitatively predicted to have approximately $75 \%$ of species having gone extinct (Jablonski 1994; Barnosky et al. 2011).

Global extinction: When it is beyond reasonable doubt that the last individual of a taxon has died (IUCN 2017).
Local extinction: The loss of a species from a local community or in part of its geographical range.

Biotic homogenization: The process where native species (losers) are replaced by more widespread, human-adapted species (winners). These are often non-native species (McKinney and Lockwood 1999).

- Loser species (Losers): Species that are declining due to human activities in the Anthropocene. These are typically geographically restricted, native species with sensitive requirements, which cannot tolerate human activities.

- Winner species (Winners): Species that not only resist geographic range decline in the Anthropocene, but also expand their ranges. These are typically widespread generalists which thrive in human-altered environments.

Defaunation: The human induced loss of species and populations of animals, along with declines in abundance or biomass (Young et al. 2016).

Ecological extinction: Occurs when species are extant but their abundance is too low to perform their functional roles in the ecological community and ecosystem (McCauley et al. 2015).

\section{Diversity terms}

Local diversity: The number of species in an area at a local spatial scale.

Spatial beta diversity: The change in species composition across space, i.e., the difference in species composition between two local communities. It is frequently quantified as the change in species composition with distance (McGill et al. 2015).

Temporal beta diversity (turnover): The change in species composition through time, i.e., the difference in species composition in a local community at two points in time.

Functional diversity: The range of functions performed by organisms in an ecological community or an ecosystem (Petchey and Gaston 2006). 
Table 4.1 The five most recent global estimates of the number of marine eukaryotic species based on a variety of methods (see Supplementary Material A for an overview of the different methods). The proportion of described species is calculated using 239,634 described species based on the number of species in the World Register of Marine Species database (WoRMS Editorial Board 2018, 15th April 2018; http://www.marinespecies.org/) and the mean or midpoint of the different estimates of total species numbers

\begin{tabular}{llll}
\hline References & Estimation method & Estimated species & Described species (\%) \\
\hline Mora et al. (2011) & Higher taxonomic extrapolation & $2,210,000 \pm 182,000^{\mathrm{a}}$ & 11 \\
Costello et al. (2010) & Expert opinion & $1,000,000-1,400,000^{\mathrm{b}}$ & 20 \\
Appeltans et al. (2012) & Expert opinion & $704,000-972,000^{\mathrm{b}}$ & 29 \\
& Past discovery rate extrapolation & $540,000 \pm 220,000^{\mathrm{a}}$ & 44 \\
Costello et al. (2012) & Expert opinion & $295,000-321,000^{\mathrm{b}}$ & 78 \\
\hline
\end{tabular}

${ }^{a}$ means \pm standard errors; branges

tal fluctuations (McCann 2000; Schindler et al. 2015). As such, having several species with similar functional roles can maintain ecosystem functioning through time.

Clearly, understanding how ecosystem function and service delivery will change through time requires knowledge of biodiversity and its temporal dynamics. As a contribution to this goal, we review the status of marine eukaryotic species (referred to as species hereafter) diversity in space and time in the Anthropocene. First, many biodiversity targets, such as those in the CBD, reflect known species. Thus, we briefly review the knowledge of global marine species diversity. Secondly, the current "biodiversity crisis" suggests there is a rapid loss of species diversity. As such, we examine trends in the loss of marine species diversity at multiple spatial and temporal scales, and its potential implications for ecosystem functioning and stability over time. Doing so, we summarize the main threats to marine biodiversity. Thirdly, we argue that focusing on losses of species diversity inadequately reflects the changes currently occurring in the marine realm. Therefore, we call for a greater emphasis on trends in abundance, population sizes, and biomass through time to better characterize the pervasiveness of anthropogenic impacts on the marine realm. Finally, we develop the greatest threats that are negatively affecting marine species in more detail, and discuss what measures are being employed to mitigate these risks. Our review focuses on species richness as a measure of biodiversity, as this is the most commonly used metric in conservation biology and ecology (Gaston 2010).

\subsection{Global Marine Species Diversity}

How many species inhabit the oceans and how many do we know about? The five most recent estimates of extant marine species using several indirect methods range from $\sim 300,000$ to 2.2 million, a full order of magnitude (Table 4.1; Supplementary Material A). Of these estimated species, approximately 240,000 have been described (WoRMS Editorial Board 2018 as of 15 April 2018). This suggests that between 11 and $78 \%$ of all marine species have been discovered and described, and reveals high levels of uncertainty in our knowledge of global marine biodiversity. This uncertainty is particularly prevalent in under sampled marine habitats such as the deep sea (Bouchet et al. 2002; Webb et al. 2010), and in taxonomic groups with few taxonomic experts (Costello et al. 2010; Griffiths 2010). Moreover, many marine species are small $(<2 \mathrm{~mm})$ and cryptic, and have only begun to be discovered with new molecular methods (de Vargas et al. 2015; Leray and Knowlton 2016). Thus, there is considerable uncertainty in estimates of how many marine species there are, along with potentially low levels of taxonomic knowledge about these species.

Incomplete knowledge of marine species diversity has serious implications for marine conservation. First, targeted conservation efforts that adequately represent local and regional biodiversity can only be effectively implemented with adequate biodiversity data (Balmford and Gaston 1999; Brito 2010). Without knowing how many species there are, there is no way to know whether we are effectively conserving marine diversity in different regions and marine groups. Indeed, decisions made using incomplete taxonomic knowledge have been shown to inadequately represent biodiversity if species are continually discovered and described (Bini et al. 2006; Grand et al. 2007). Second, a species must be described to be assessed by the International Union for Conservation of Nature (IUCN 2017; Box 4.2). Currently, the coverage of marine species on the IUCN Red List is severely incomplete (Fig. 4.1a). This is important as the IUCN is the global authority for assigning conservation statuses and assessing species extinction risks (IUCN 2017). If conservation efforts are to adequately represent marine biodiversity and understand the conservation status of marine species, it may be key to improve estimates of global marine diversity and marine taxonomic knowledge.

\subsection{Trends in Marine Biodiversity Loss and its Consequences}

The simplest, and perhaps most cited, type of biodiversity loss is global extinction (see Box 4.1). Global extinctions occur when the last individual of a species has died. While 


\section{Box 4.2 Spotlight on the IUCN Red List of Threatened Species}

The IUCN Red List constitutes the most comprehensive database of the global conservation status of species (IUCN 2018). It contains a range of information related to species population size and trends, geographic distribution, habitat and ecology, threats, and conservation recommendations. The assignment of a conservation status is based on five categories: (i) population trends; (ii) geographic range size trends; (iii) population size; (iv) restricted geographic distribution; and (v) probabilistic analyses of extinction risk. The magnitude of these five categories places a species into a conservation category. The categories used in this review are detailed below. Species that are vulnerable, endangered, or critically endangered are considered threatened with extinction.

- Data deficient (DD): There is insufficient population and distribution data to assess the extinction risk of the taxon.

- Least concern (LC): Based on the available data, the taxon does not meet the criteria to be NT, VU, $\mathrm{EN}$, or CR.

- Near threatened (NT): Based on the available data, the taxon does not meet the criteria to be VU, $\mathrm{EN}$, or CR but is expected to qualify for one of the threatened categories in the future

- Vulnerable (VU): The available data suggest that the taxon faces a high risk of extinction in the wild.

- Endangered (EN): The available data suggest that the taxon faces a very high risk of extinction in the wild.

- Critically endangered (CR): The available data suggest that the taxon faces an extremely high risk of extinction in the wild.

- Extinct in the wild (EW): The taxon is known only to survive in cultivation, in captivity, or as a naturalized population well outside the past range.

- Extinct (EX): There is no reasonable doubt that the last individual of a taxon has died.

we may remain unaware of the current global extinction risk of many marine species, the fossil record can provide an insight into how long species typically survived before anthropogenic stressors became widespread. The oldest known horseshoe crab fossil dates back 445 million years (Rudkin et al. 2008). Known as a "living fossil," the horseshoe crab is part of a small group of organisms which have survived millions of years of Earth's history. The persistence of the horseshoe crab through time is, however, an exception.
Over $90 \%$ of marine organisms are estimated to have gone extinct since the beginning of life (Harnik et al. 2012). This rate of natural species extinction through time is referred to as background extinction (see Box 4.1) and specifically refers to extinction rates prior to the influence of humans (Pimm et al. 1995). Widely accepted historic estimates range between 0.01 and 2 extinctions per million species-years (E MSY'-1; see Box 4.1, Table 4.2). The background extinction rate has been thoroughly investigated to contextualize the anthropogenic influence on accelerating species extinctions. It also provides a benchmark to differentiate intervals of exceptional species losses or "mass extinction events" from the prevailing conditions in Earth's history.

Current extinction rates of $100 \mathrm{E} \mathrm{MSY}^{-1}$ are at least 10-1000 times higher than the background rates, suggesting that we have entered the sixth mass extinction event in Earth's history (Pimm et al. 1995, 2014; Barnosky et al. 2011). Increases in atmospheric $\mathrm{CO}_{2}$ and ocean acidification measured for the current proposed sixth mass extinction have been associated with three of the five previous mass extinctions (Kappel 2005; Harnik et al. 2012). It is, however, the first time that these changes are anthropogenically driven. The impacts of these anthropogenic stressors are observed directly in vertebrate extinctions. Over 468 more vertebrates have gone extinct since 1900 AD than would have been expected under the conservative background extinction rate of $2 \mathrm{E} \mathrm{MSY}^{-1}$ (Ceballos et al. 2015). This increased extinction rate argues in favor of anthropogenic causes for the current mass extinction.

The high extinction rates currently observed are largely due to the loss of terrestrial species (Barnosky et al. 2011; Ceballos et al. 2015). In contrast, estimated extinction rates of marine species have been closer to background extinction rates (Table 4.2; Harnik et al. 2012). Records from the IUCN indicate that only 19 global marine extinctions have been recorded in the last ca. 500 years (IUCN 2017). Conversely, 514 species from the terrestrial realm have gone extinct in the same timeframe (McCauley et al. 2015). The asymmetry in the number of extinctions between the marine and terrestrial environments has led to suggestions that defaunation (see Box 4.1), or human-induced loss of animals, has been less severe in the marine realm and may be just beginning (e.g., McCauley et al. 2015). Indeed, although marine resources have been harvested by humans for over 40,000 years, the intense exploitation of marine life is a relatively recent phenomenon compared to the terrestrial realm, only commencing in the last few hundred years (O'Connor et al. 2011; McCauley et al. 2015). Additionally, multiple biological factors have been proposed to explain the observed low extinction rates of marine species. Background extinction rates of marine species have decreased with time, which suggests that extinction susceptible clades have already gone extinct (Harnik et al. 2012). Moreover, marine species tend 

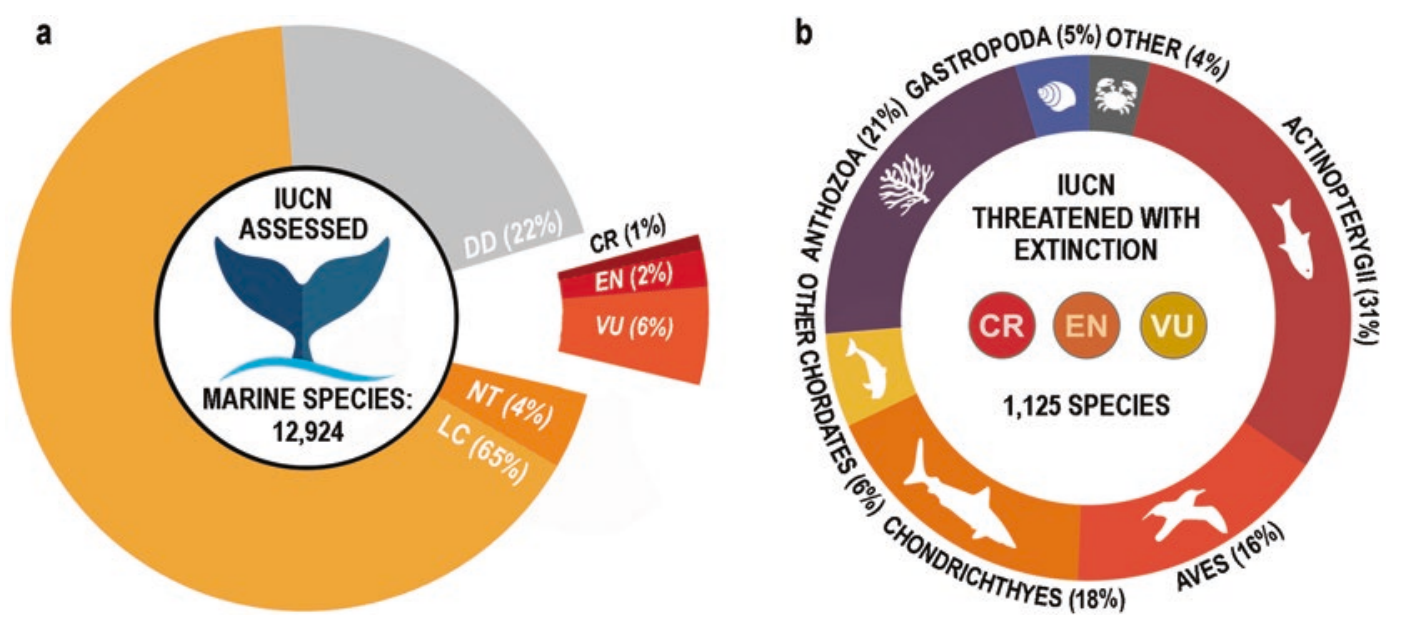

Fig. 4.1 (a) The conservation status of 12,924 IUCN-assessed marine species. Only 10,142 are in a category other than data deficient, an inadequate level of assessment (IUCN 2018). This represents $4.2 \%$ of currently described marine species (WoRMS Editorial Board 2018, 15 April 2018), and only between 0.5 and $3.3 \%$ of the estimated total marine species. Of the assessed species, $11 \%$ are either critically endangered (CE), endangered (EN), or vulnerable (VU), and are thus considered threatened with extinction. (b) Taxonomic distribution of marine species threatened with extinction, as defined by being classified CR,
EN, or VU. Of these assessments, $64 \%$ are species from well-described groups (Webb and Mindel 2015). Furthermore, 64 of 88 recognized marine groups (groups as per Appeltans et al. 2012) had no IUCN assessed species (Webb and Mindel 2015). The "other chordates" category includes Mammalia, Myxini, Reptilia, and Sarcopterygii, and "other" category includes Polychaeta, Insecta, Malacostraca, Maxillopoda, Merostomata, Hydrozoa, and Holothuroidea. These were grouped due to low species availability. Data extracted from IUCN (2018)
Table 4.2 Various estimates of the background extinction rate using different methods and taxonomic groups. These rates are 10-1000 times lower than estimates of current extinction rates (Pimm et al. 1995, 2014; Barnosky et al. 2011). Extinction rates are measured in $\mathrm{E} \mathrm{MSY}^{-1}$, or the number of extinctions (E) per million species-years (MSY) (Pimm et al. 1995, 2014; Box 4.1)

\begin{tabular}{|c|c|c|c|}
\hline References & $\begin{array}{l}\text { E MSY }^{-1} \\
\text { estimate }\end{array}$ & Taxonomic/animal group & Method \\
\hline $\begin{array}{l}\text { Pimm } \\
\text { et al. } \\
(1995)\end{array}$ & $0.1-1$ & Marine invertebrates & Fossil record \\
\hline $\begin{array}{l}\text { Barnosky } \\
\text { et al. } \\
(2011)\end{array}$ & 1.8 & Vertebrates & Fossil record \\
\hline $\begin{array}{l}\text { Harnik } \\
\text { et al. } \\
(2012)\end{array}$ & $\begin{array}{l}0.01- \\
0.27\end{array}$ & $\begin{array}{l}\text { Cetacea, marine Carnivora, } \\
\text { Echinoidea, } \\
\text { Chondrichthyes, } \\
\text { Scleractinia, Gastropoda, } \\
\text { Crustacea, Osteichthyes, } \\
\text { Bivalvia, Bryozoa, } \\
\text { Brachiopoda }\end{array}$ & $\begin{array}{l}\text { Fossil and } \\
\text { historical } \\
\text { records }\end{array}$ \\
\hline $\begin{array}{l}\text { De Vos } \\
\text { et al. } \\
(2015)\end{array}$ & 0.1 & $\begin{array}{l}\text { Chordata, Mollusca, } \\
\text { Magnoliophyta, and } \\
\text { Arthropoda }\end{array}$ & $\begin{array}{l}\text { Molecular } \\
\text { phylogenies }\end{array}$ \\
\hline
\end{tabular}

to have traits which are associated with a reduced extinction risk, such as larger geographic range sizes and lower rates of endemism (Gaston 1998; Sandel et al. 2011). Finally, on average, marine species can disperse further than terrestrial species and, thus, may respond better to environmental changes (Kinlan and Gaines 2003).
Nonetheless, the suggestion that extinction rates in the marine realm are lower than in the terrestrial realm is, however, not fully supported for several reasons. First, current marine and terrestrial extinctions may not be directly comparable. Species must be discovered and described taxonomically before they can be given a conservation status or shown to be extinct (Costello et al. 2013). As such, if the marine and terrestrial realms have variable rates of species discovery, taxonomic description, or conservation assessment, the detectability of their respective extinctions could differ (Pimm et al. 2014). The oceans are vast and largely inhospitable to humans. This makes marine systems particularly challenging to study. As a result, large parts of the marine realm are undersampled, there is a lack of taxonomic expertise for certain groups and, thus, marine extinction rates may have been underestimated (see Section 2). Although estimates of global species richness vary widely, there seems to be little difference in the proportion of marine and terrestrial species that have been described (ca. 30\%, Appeltans et al. 2012; Pimm et al. 2014). However, of all taxonomically described species, the IUCN has assessed proportionally fewer marine than terrestrial species (3\% vs. $4 \%$ ), which might partially explain the discrepancy in extinction rates (Webb and Mindel 2015). This premise is supported by Webb and Mindel (2015), who found that there is no difference in extinction rate between marine and terrestrial species for marine groups that have been well-described and wellassessed. Thus, studies suggesting that marine extinction 
rates are low compared to terrestrial rates may be inaccurate.

Secondly, although global extinctions are important evolutionary events, and tools for highlighting conservation issues (Rosenzweig 1995; Butchart et al. 2010), they inadequately reflect the consequences of anthropogenic impacts on the ocean. There is little doubt that extinction rates are increasing at local and global scales (McKinney and Lockwood 1999; Butchart et al. 2010; Barnosky et al. 2011). However, local-scale time series (between 3 and 50 years) covering a variety of taxa and marine habitats around the world show no net loss in species richness through time (Dornelas et al. 2014; Elahi et al. 2015; Hillebrand et al. 2018). These time series analyses have recently received substantial criticism as synthetized by Cardinale et al. (2018). For instance, they are not spatially representative and do not include time series from areas which have experienced severe anthropogenic impacts such as habitat loss. Habitat loss and reduced habitat complexity due to anthropogenic disturbance may indeed reduce local-scale species richness and abundance in a variety of marine ecosystems (Airoldi et al. 2008; Claudet and Fraschetti 2010; Sala et al. 2012). Still, despite the limitations of the time series and the contradictory evidence from local-scale comparisons, the time series analyses illustrate an important point: changes in biodiversity at global scales may not always be evident in the properties of local-scale communities.

Focusing on extinctions and reductions in species richness can also hide changes in community composition (McGill et al. 2015; Hillebrand et al. 2018). There is increasing evidence that the destruction and modification of structurally complex habitats is leading to the rapid disappearance of the diverse communities they harbor at local, regional, and global scales (Lotze et al. 2006; Airoldi et al. 2008). For example, kelp forests and other complex macroalgal habitats have declined notably around the world, most likely due to overfishing and reduced water quality (Steneck et al. 2002). Similarly, $85 \%$ of oyster reefs, once an important structural and ecological component of estuaries throughout the world, have been lost (Beck et al. 2011). Globally, coastal habitats are among the most affected habitats (Halpern et al. 2015). This loss in habitat complexity can lead to geographic range contraction or local extinction (see Box 4.1) of associated resident species (losers; see Box 4.1), and the range expansion of a smaller number of cosmopolitan "invaders" with an affinity for human-altered environments (winners; see Box 4.1; McKinney and Lockwood 1999; Olden et al. 2004; Young et al. 2016). Thus, although local species richness may remain stable or even increase, there may be substantial changes in species composition through time, or temporal species turnover (see Box 4.1; Dornelas et al. 2014; Hillebrand et al. 2018). If resident species (losers) are going extinct locally and being replaced by these cosmopolitan invaders (winners), it is likely that adjacent communities in space will become more similar. This will result in declines in spatial beta diversity: the change in species composition across space (see Box 4.1). The consequence of this would be lower regional species richness, or large-scale biotic homogenization (see Box 4.1; McKinney and Lockwood 1999; Sax and Gaines 2003).

Biotic homogenization is not a new phenomenon, however, the process might have accelerated for several reasons (McKinney and Lockwood 1999; Olden et al. 2004). First, the breakdown of biogeographic barriers following the emergence of global trade in the nineteenth century (O'Rourke and Williamson 2002) has led to the widespread introduction of species out of their native range (Molnar et al. 2008; Hulme 2009; Carlton et al. 2017). As local habitat disturbance typically creates unoccupied niches, invasion by exotics is facilitated and, thus, local endemic species can be replaced with widespread species (Bando 2006; Altman and Whitlatch 2007; McGill et al. 2015). Although only a small fraction of non-native species successfully disperse and invade new habitats, the ecological and economic impacts are often significant (Molnar et al. 2008; Geburzi and McCarthy 2018). Secondly, similar types of habitat destruction or modification across space are leading to large-scale reductions in habitat diversity (McGill et al. 2015). For example, trawling activities have been reported on $75 \%$ of the global continental shelf area, which has considerably homogenized benthic habitats in space (Kaiser et al. 2002; Thrush et al. 2006). Moreover, vast dead zones emerge annually following the runoff of excessive nutrients and sediment from land, leading to eutrophication of coastal areas, increased algal blooms, and finally hypoxic aquatic conditions (Crain et al. 2009). This type of pollution can severely affect the growth, metabolism, and mortality of marine species (Gray 2002), and lead to large-scale homogenization of marine habitats and associated biological communities (Thrush et al. 2006). Finally, the rising temperatures associated with climate change, which is considered one of the most serious emerging threats to marine species and ecosystems (Harley et al. 2006; Rosenzweig et al. 2008; Pacifici et al. 2015), is causing species' range expansions and contractions, consequently altering spatial diversity patterns (Harley et al. 2006; Sorte et al. 2010). On average, marine organisms have expanded their distribution by approximately $70 \mathrm{~km}$ per decade in response to climate change, mostly in a poleward direction (Poloczanska et al. 2016). Polar species, which are unable to shift their range further poleward, are likely to be replaced by species expanding from temperate regions, leading to a reduction in both regional and global diversity.

Currently, there is insufficient evidence to quantify the extent of biotic homogenization in marine communities and whether there are trends through time (Airoldi et al. 2008; 
McGill et al. 2015). There are, however, some examples of anthropogenic disturbances reducing spatial beta diversity in certain marine ecosystems. For instance, increased sedimentation has been shown to reduce spatial beta diversity between vertical and horizontal substrates in subtidal algal and invertebrate communities (Balata et al. 2007a, b). Furthermore, there is evidence that loss of habitat through bottom trawling does reduce spatial beta diversity, thus, reducing regional species richness (Thrush et al. 2006). Moreover, a recent analysis demonstrated declines in the spatial beta diversity of marine groundfish communities in the past 30 years, which is thought to be linked to recent ocean warming (Magurran et al. 2015). However, to our knowledge, this is the only explicit quantification of trends in spatial beta diversity through time in the marine realm. Moreover, the relative roles of species introductions, habitat loss and modification, and range shifts due to climate change are poorly known. Thus, understanding how biodiversity at broader scales is changing represents an important future challenge in marine species conservation.

The non-random distribution of winners and losers among taxonomic and functional groups is likely to worsen and intensify biotic homogenization. Certain ecological and life history traits influence the vulnerability of species to extinction (Roberts and Hawkins 1999; Dulvy et al. 2003; Reynolds et al. 2005; Purcell et al. 2014). For example, rare, large, highly specialized species with small geographic ranges are more likely to experience range contractions or local extinctions under human pressure (Dulvy et al. 2003). Conversely, smaller generalist species with a widespread geographic range and traits which promote transport and establishment in new environments tend to respond better to these pressures (McKinney and Lockwood 1999). Traits favoring either extinction or range expansion in the Anthropocene tend to be phylogenetically nested within certain groups of closely related species on the tree of life (McKinney 1997). Consequently, some taxonomic groups are more vulnerable to decline and extinction threats (see Fig. 4.1b, Lockwood et al. 2002). The unique morphological and behavioral adaptations within these groups are thus vulnerable to loss, especially if taxa are species-poor (McKinney and Lockwood 1999). Similarly, the winners of the Anthropocene tend to be clustered within certain taxa, further contributing to global biotic homogenization and losses in regional species diversity.

The implications of a loss in local diversity (see Box 4.1) for ecosystem functions and services are well-studied (Cardinale et al. 2012; Gamfeldt et al. 2015; Lefcheck et al. 2015), but the consequences of reductions in beta diversity at various spatial and temporal scales remain poorly understood. Studies on biotic homogenization usually describe the increased similarity in species composition between communities, driven by the replacement of many specialized species with few widespread generalist invaders (McKinney and Lockwood 1999; Olden et al. 2004). However, the presence of complementarity and selection effects on ecosystem functions suggests that the consequences of biotic homogenization on ecosystem functioning is best studied in terms of the diversity and composition of functional groups in the community (Olden et al. 2004; Palumbi et al. 2009). The spatial redistribution of taxonomic groups due to biotic homogenization may also alter the composition and variation in the functional groups of communities across marine habitats. The consequences of these changes across space for marine ecosystem functioning are currently not well-known.

The loss of specialists and replacement by generalist species or functional groups may negatively affect ecosystem functioning at multiple spatial scales. There is a trade-off between a species' ability to use a variety of resources and the efficiency by which each of these resources is used (Clavel et al. 2011). At local scales, specialists are more efficient at using few specific resources when the environment is stable (Futuyama and Moreno 1988; Colles et al. 2009). For example, specialist coral reef fish grow faster than generalists in a few habitats, but the growth rate of generalists is more consistent across a range of habitats (Caley and Munday 2003). Thus, the replacement of specialized species with generalists will lead to reduced ecosystem functioning on a local scale (Clavel et al. 2011; Cardinale et al. 2012). On a broader spatial scale, specialist species replace each other along environmental gradients, with each species optimally utilizing the resources in their specific environment (Rosenzweig 1995). For example, in marine systems, monocultures of well-adapted species had better ecosystem functioning than diverse communities on a local scale, even though diverse communities outperformed the average monoculture (Gamfeldt et al. 2015). This suggests that locally adapted specialist species are important for ecosystem functioning. As a result, the decrease in species turnover along environmental gradients following biotic homogenization may reduce the prevalence of locally adapted species, which in turn may cause a reduction in ecosystem functioning on a broader scale. In addition, functional homogenization between communities will likely reduce the range of species-specific responses to environmental change (Olden et al. 2004). Ecological communities will become increasingly synchronized when facing disturbance, reducing the potential for landscape or regional buffering of environmental change, and finally reducing the stability of ecosystem functions (Olden et al. 2004; Olden 2006). Thus, even though generalist species are more resilient to environmental change on a local scale, at broader spatial scales, the reduced number of specialists may negatively affect the stability of the system (Clavel et al. 2011). Improving our understanding of the functional consequences of biotic homogenization is, thus, key to understanding how current biodiversity trends 
will impact ecosystem functioning and the delivery of associated ecosystem services.

\subsection{Looking Beyond Extinctions: Population Declines in the Marine Realm}

Understanding extinctions and how biodiversity is changing through time and space is an important aspect of marine conservation. However, extinctions and declines in species richness do not fully reflect the extent of humanity's impact on the marine realm (McCauley et al. 2015). At the base of marine biological communities are populations of interacting species. In the marine realm, population declines are ubiquitous and often severe (Jackson et al. 2001). Therefore, to understand human impacts on marine biodiversity, and its consequences for ecosystem processes, it is crucial to understand the associated changes in species' population dynamics.

Between 1970 and 2012, the average size of 5,829 populations of 1,234 species of marine vertebrates has declined by $49 \%$ (WWF 2015). Overexploitation is the major cause of these declines, both through direct mortality of target species and multiple collateral effects on non-target species (Crain et al. 2009; WWF 2015). Harvested fish populations are routinely depleted by 50-70\% (Hilborn et al. 2003), and losses of up to $90 \%$ are common (Myers and Worm 2005). These population declines are, however, not confined to vertebrates. The commercial exploitation of the white abalone in California and Mexico led to a reduction in population size to $0.1 \%$ of estimated pre-overexploitation levels (Hobday et al. 2000). Similarly, the increased demand for sea cucumbers as luxury food or traditional medicine in the last three decades has led to severe population declines, with $69 \%$ of sea cucumber fisheries now considered overexploited (Anderson et al. 2010). Thus, intensive harvesting of marine resources in recent times has caused widespread declines in several targeted marine species populations.

Overexploitation of targeted species can also affect populations of other marine species indirectly through bycatch, injury-induced mortality, or altered species interactions following population declines of target species (Crain et al. 2009). For example, global estimates suggest that as much as 39.5 million metric tons of fish may be caught as bycatch each year (Davies et al. 2009). However, fisheries bycatch is not restricted to other fish or invertebrates typically caught in industrial fisheries. Bycatch affects a variety of taxa such as seabirds, sea turtles, and marine mammals and has led to population declines of several well-known species including the Pacific leatherback turtle (Dermochelys coriacea), the Amsterdam albatross (Diomedea amsterdamensis), and the vaquita (Phocoena sinus) (Lewison et al. 2014). In addition, interactions with fishing vessels and other boats constitute an important cause of injury-induced mortality, especially for coastal air-breathing marine fauna such as marine mammals and reptiles (Shimada et al. 2017). In Moreton Bay (Queensland, Australia), for instance, the most commonly known causes of mortality for dugongs (Dugong dugon) were vessel strikes, trauma, and netting, and sea turtles are similarly impacted by boat strikes and discarded fishing gear (Lanyon 2019).

Notwithstanding the negative effects of bycatch and modern fishing methods, altered species interactions following the population depletion of targeted species, and the associated changes in food web structure, are also believed to have considerable collateral effects on non-targeted marine populations (Österblom et al. 2007; Estes et al. 2011). Reductions in the population size of a trophic level caused by overexploitation can induce correlated changes in the abundance of interacting species (Frank et al. 2005; Johannesen et al. 2012). For example, in temperate rocky reefs, reduced predation pressure due to overexploitation of herbivore predators can cause significant increases in the abundance and size of herbivorous invertebrates like sea urchins and chitons (Fig. 4.2, Ling et al. 2015). The associated increase in herbivory decreases macroalgal abundance (e.g., kelp) (Steneck et al. 2013). While these trophic cascades_or indirect effects on the population abundance of species at two/more trophic links from the primary one (Frank et al. 2005) —are frequently studied in relation to apex predator depletion and the associated loss of top-down control (Box 4.3), they are not restricted to high trophic levels. In the Barents Sea, changes in the abundance of the middle trophic level capelin (Mallotus villosus) can cause abundance changes in both high and low trophic levels (Johannesen et al. 2012). Thus, in marine systems, population sizes are generally coupled to populations of interacting species. As a result, any anthropogenically driven population reduction can indirectly affect population dynamics across trophic levels and over whole food webs.

In certain cases, changes in the abundance of different trophic groups can cause significant food web reorganizations (Baum and Worm 2009; Estes et al. 2011). Food web reorganizations may manifest as sudden shifts to a new ecosystem state, frequently termed regime shifts (Sguotti and Cormon 2018). Regime shifts are important because alternate ecosystem states can be maintained by internal feedback mechanisms which prevent a system from reverting back to a previous state (Scheffer et al. 2001). In the temperate rocky reef example, some areas that were previously dominated by macroalgae have shifted to a barren state dominated by sea urchin and crusting algae as a result of reduced predation pressure (Steneck et al. 2013). A combination of feedbacks including high juvenile sea urchin abundance, juvenile facilitation by adult sea urchins, and sea urchin-induced mortality of juvenile kelp maintain the system in this new state (Ling 
Fig. 4.2 Schematic

representation of the changes in abundance between trophic groups in a temperate rocky reef ecosystem. (a)

Interactions at equilibrium

(b) Trophic cascade following disturbance. In this case, the otter is the dominant predator and the macroalgae are kelp. Arrows with positive (green, + ) signs indicate positive effects on abundance while those with negative (red, -) indicate negative effects on abundance. The size of the bubbles represents the change in population abundance and associated altered interaction strength following disturbance. Based on Estes et al. (1998) a

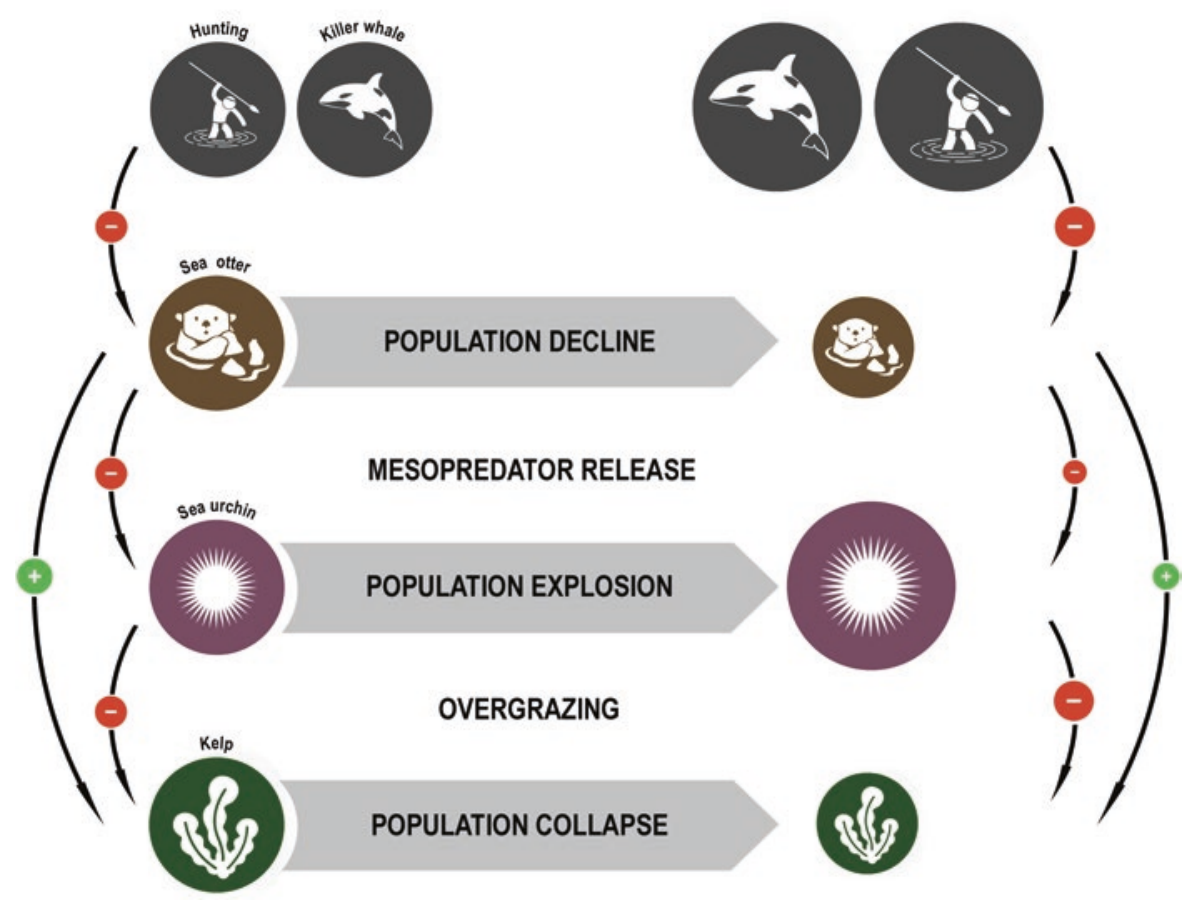

et al. 2015). These feedbacks mean that even increasing predator abundance to historical highs may not shift the ecosystem back to a macroalgae-dominated state (Sguotti and Cormon 2018). Ecosystems can be resilient to such regime shifts if abundance declines in one species can be compensated by other species in a similar trophic level (Mumby et al. 2007). As a result, regime shifts may only occur longafter overexploitation has begun when all species of a trophic level have suffered declines in abundance and compensation is no longer possible (Jackson et al. 2001).

Overexploitation is, however, not the only anthropogenic stressor negatively affecting marine populations. Habitat modification and destruction, being the reduction in habitat quality or complete removal/conversion of ecosystems and their related functions, have driven drastic changes in marine habitats. These further result in declines in marine populations (Lotze et al. 2006; Knapp et al. 2017). Globally, coastal development has contributed to the widespread degradation or loss of coastal habitats. The annual loss of coastal habitat has been estimated to be between 1-9\% for coral reefs (Gardner et al. 2003; Bellwood et al. 2004) and 1.8\% for mangroves (Valiela et al. 2001), and seagrass beds have been disappearing at a rate of $7 \%$ annually since 1990 (Waycott et al. 2009).

Additionally, pollution can have important consequences for marine populations. For instance, the amount of debris in our oceans is rapidly increasing and is currently affecting an estimated 663 species through entanglement or ingestion, $15 \%$ of which are threatened with extinction (Derraik 2002;
Secretariat of the Convention on Biological Diversity and the Scientific and Technical Advisory Panel 2012; VillarrubiaGómez et al. 2018). Although evidence for population-level impacts is scarce, marine debris is believed to have contributed to the population decline of several threatened species such as the Northern fur seal (Callorhinus ursinus) and the Hawaiian monk seal (Monachus schauinslandi) (FrancoTrecu et al. 2017). The reported number of individuals affected by marine debris suggests this threat might be pervasive (Secretariat of the Convention on Biological Diversity and the Scientific and Technical Advisory Panel 2012; Wilcox et al. 2015). Furthermore, deaths from ingesting marine debris can happen in the open ocean with no evidence ever washing onto beaches. Thus, the frequency of mortality from debris may actually be higher than currently perceived.

Biological invasions also represent a serious disruption to the balance of ecosystems, which can have severe consequences for the population abundance of prey species or competitors. Albins and Hixon (2013) found that the introduction of the Indo-Pacific lionfish (Pterois volitans) on Atlantic and Caribbean coral reefs poses a serious threat to coral reef fishes, reducing prey fish recruitment and abundance compared to control sites by 79 and $90 \%$, respectively. This loss of prey species increases competition for the same depleted resource base, negatively impacting native predators such as the coney (Cephalopholis fulva).

Finally, climate change driven by the anthropogenic emission of greenhouse gases represents an emerging threat to 
marine populations. Climate change has led to rising global atmospheric and ocean temperatures, in addition to increasing the ocean $\mathrm{pH}$ (ocean acidification), as the oceans take up greater amounts of $\mathrm{CO}_{2}$ (IPCC 2013). The consequences for marine populations are wide and varied, altering species' morphology, behavior, and physiology (Harley et al. 2006; O'Connor et al. 2007; Rosenzweig et al. 2008). For example, warmer ocean temperatures have led reef-building corals to live in the upper limits of their thermal tolerance, and prolonged periods of thermal stress can result in mass coral bleaching and disease outbreaks (Scavia et al. 2002; HoeghGuldberg et al. 2007; Harvell et al. 2009). Furthermore, the recurring frequency of increasing thermal pressure reduces the capacity of coral reefs to recover between events, decreasing their resilience to future change (Baker et al. 2008). Additionally, calcareous organisms such as mollusks, crustaceans, some species of algae/phytoplankton, and reefbuilding corals are vulnerable to ocean acidification, as calcification rates decline notably in high $\mathrm{pH}$ environments, and calcium carbonate dissolves (Orr et al. 2005; HoeghGuldberg et al. 2007; Guinotte and Fabry 2008). Climate change is considered one of the most serious threats to marine species and ecosystems at present, as the potential for marine species to adapt to the changing environmental conditions, and the serious implications it may have on the functioning of marine ecosystems, still remain largely unknown (Pacifici et al. 2015).

These diverse anthropogenic stressors are expected to accelerate in the future and alter patterns of global marine biodiversity (Jones and Cheung 2014), with consequences for species survival, economics, and food security (Barange et al. 2014). Emerging evidence suggests that the various stressors may interact to increase the extinction risk of marine species (Brook et al. 2008; Knapp et al. 2017). This indicates that the synergistic effects of multiple stressors may exceed the additive combination of any single stressor (Crain et al. 2008; Harnik et al. 2012). For example, changes in ocean temperature and chemistry might increase the vulnerability of some species to overexploitation by altering demographic factors (Doney et al. 2012; Harnik et al. 2012). The amplifying nature and dynamics of these synergistic interactions are poorly known for most stressors and requires further investigation.

Despite these overarching negative trends in marine species populations, certain species, trophic levels, and body sizes are more susceptible to population declines than others. Both large and small-scale fisheries disproportionately target large species at high trophic levels (Myers and Worm 2003; Kappel 2005; Olden et al. 2007). Additionally, large bodied species tend to have smaller population sizes as well as slower growth and reproduction rates, making them intrinsically more vulnerable to overexploitation (Roberts and Hawkins 1999; García et al. 2008; Sallan and Galimberti
2015). Consequently, large and high trophic level marine species have declined more rapidly and severely, and have been found to be at greater risk of extinction (Olden et al. 2007). Over $90 \%$ of large pelagic fish have experienced range contractions (Worm and Tittensor 2011) and the biomass of commercially valuable large species such as tuna is estimated to have declined by $90 \%$ relative to pre-industrial levels (Myers and Worm 2003). In certain regions, shark populations have declined by over 90\% (Baum et al. 2003;

\section{Box 4.3 Consequences of Apex Consumer Loss on Biological Communities}

From the beginning of human impact in the Pleistocene, the marine realm has seen a disproportionate loss of larger-bodied animals (Smith et al. 2003). There is mounting evidence that large fauna has a strong influence on the structure, functioning, and resilience of marine ecosystems for several reasons (Duffy 2002; Myers et al. 2007). Large animals are often apex consumers which exert top-down population control on prey communities through direct mortality or fearinduced behavioral alterations (Creel et al. 2007; Creel and Christianson 2008; Heithaus et al. 2008; Laundré et al. 2010). Additionally, large animals can be ecosystem engineers, increasing the structural or biogeochemical complexity of their ecosystem either behaviorally or morphologically (e.g., whale falls creating novel ecosystems, Mills et al. 1993; Jones et al. 1994; Coleman and Williams 2002). As such, the consequences of the defaunation of large fauna are not retained within the impacted group, but affect multiple trophic levels in the community.

The loss of top-down control following apex consumer decline is often followed by population increases of medium-sized vertebrate prey, known as mesopredator release (Baum and Worm 2009). The effects of this decline are, however, not just restricted to their immediate prey, but often propagate down the food web, resulting in inverse patterns of increase/decrease in population abundance of lower trophic levels - a process known as trophic cascading (Paine 1980; Baum and Worm 2009). For example, Myers et al. (2007) found that the near-complete eradication of shark populations on the eastern seaboard of the USA led to the population explosion of mesopredatory elasmobranchs such as the cownose ray, increasing in abundance with order of magnitude in four decades. Moreover, the effects of the removal of this functional group cascaded down the food chain. Cownose rays

(continued) 


\section{Box 4.3 (continued)}

now inflict a near-complete mortality on their bay scallop prey populations during migration periods, which has led to the discontinuation of North Carolina's traditional scallop fisheries. Additionally, bay scallops are expected to be replaced by infaunal bivalves, which could cause the uprooting of seagrass and, consequently, the loss of this habitat's function as nurseries and feeding grounds. Thus, losses of apex consumers can destabilize ecological communities, and the consequences of these cascading effects may be multiple.

Although counterintuitive, the direct mortality inflicted by apex consumers on prey species may improve the long-term survival of these prey populations. Predators eliminate sick individuals from prey populations, thus increasing the overall health of the population (Severtsov and Shubkina 2015). Moreover, the prevalence of disease epidemics is strongly linked to population density (Lafferty 2004). As such, apex consumers may inhibit disease outbreaks by suppressing prey populations below the critical host-density threshold for effective disease transmission (Packer et al. 2003). For instance, local extinction of sea otters around the California Channel Islands reduced the predation pressure on the black abalone, leading to an abalone population outbreak (Lafferty and Kuris 1993). As a result, black abalone populations increased beyond the host-density threshold, which led to an outbreak of the previously unknown rickettsial disease. The final result was a collapse of the black abalone population to levels of probable extinction (critically endangered - IUCN 2017).

The loss of large marine fauna may also affect biogeochemical cycles between the ocean and the other major reservoirs (Crowder and Norse 2008). Predators limit herbivore abundance, thus buffering herbivore effects on autotrophic organisms (Hairston et al. 1960). Autotrophs hold a high proportion of the global nonfossilized organic carbon reserves in their tissues, and are able to convert inorganic carbon to organic carbon through their photosynthetic ability (Wilmers et al. 2012). Thus, the global apex consumer losses might have altered the carbon cycle considerably. Indeed, apex consumers have been shown to significantly alter carbon capture and exchange. In the absence of sea otters, for instance, trophic cascades (Fig. 4.2) reduced the net primary production and carbon pool stored in kelp forests 12-fold, resulting in reduced carbon sequestration (Wilmers et al. 2012). Similarly, with the reduced numbers of great whales, a large part of the primary production is consumed by smaller animals with much higher mass-specific metabolic rates. This greatly reduces the overall potential for carbon retention in living marine organisms compared to preindustrial times (Pershing et al. 2010). In addition, the carbon sequestration resulting from the sinking of great whale carcasses to the deep sea declined from an estimated $1.9 \times 10^{5}$ tons $\mathrm{C}$ year ${ }^{-1}$ to $2.8 \times 10^{4}$ tons $\mathrm{C}$ year $^{-1}$ - a decrease by an order of magnitude since the start of industrial whaling (Pershing et al. 2010).

Great whales also exhibit behavioral engineering functions, the loss of which can influence the global nutrient and carbon cycling (Roman et al. 2014). Through their diving/surfacing behavior and the creation of bubble nets, great whales often break density gradients (Dewar et al. 2006), allowing an influx of nutrients to the formerly stratified and nutrientdepleted photic zone. Additionally, great whales frequently release fecal plumes and urine near the surface which brings limiting nutrients such as $\mathrm{N}$ and $\mathrm{Fe}$ from the aphotic zone above the thermocline (Roman and McCarthy 2010). Finally, through their migration from nutrient-rich high-latitude feeding grounds to nutrientpoor low-latitude calving grounds, some great whales bring limiting nutrients to tropical waters (Roman et al. 2014). These processes increase the primary production in the nutrient-poor photic zone, and in turn, increase carbon sequestration through sinking algal blooms to the deep sea (Lavery et al. 2010).

Myers et al. 2007), and reef-associated predators have shown similar declines (Friedlander and DeMartini 2002). Furthermore, in a similar time period, global whale population abundance has declined by 66-99\% compared to their pre-whaling estimates (Roman et al. 2014). The diminishing number of large apex consumers has led to a reduction in the mean trophic level and community body size of marine food webs, as species of progressively decreasing size and trophic level are targeted (Pauly et al. 1998; Jennings and Blanchard 2004). The effects of these population depletions are, however, not solely retained within their respective trophic levels or populations, but affect inter-species interactions and ecosystem stability and functioning.

Large apex consumers are often keystone species (see Box 4.1), performing crucial ecological roles within their communities (Paine 1969; Box 4.3). Other than the aforementioned potential top-down forcing they can exert on their communities, large animals can also be ecosystem engineers (see Box 4.1), acting as keystone modifiers of habitat features which are crucial to the survival of other species 
(Mills et al. 1993; Jones et al. 1994). When these engineering functions are removed, habitats generally become less complex, which decreases the diversity they can sustain. The loss of these keystone species results in the reduction of structural and functional diversity and decreases ecosystem resilience to environmental change (Coleman and Williams 2002). Thus, the near-complete elimination of large apex consumers from their ecosystems represents a major perturbation with important and far-reaching consequences for the structure, functioning, and resilience of marine ecosystems (Duffy 2002; Myers et al. 2007).

Overall, the ubiquity of marine population declines is important, as analyses quantifying the consequences of anthropogenic stressors on biodiversity routinely focus on biodiversity trends without explicitly accounting for population abundance and biomass trends (Dirzo et al. 2014; McGill et al. 2015). For instance, much of the work on ecosystem functions and services focuses on changes in local diversity, while few studies explicitly consider population declines and the subsequent changes in relative species abundance, which may be equally important (Dirzo et al. 2014; Winfree et al. 2015). In some cases, population declines have been so high that species cannot functionally interact in communities across part or all of their range (Worm and Tittensor 2011; McCauley et al. 2015). These "ecological extinctions" (see Box 4.1) are more difficult to measure and may be more widespread than currently appreciated (McCauley et al. 2015). Furthermore, unlike complete extinctions, which usually occur slowly, population declines can be very rapid and, thus, can cause rapid ecosystem changes and even regime shifts (Säterberg et al. 2013). Incorporating population and biomass trends into biodiversity monitoring, and understanding how this affects marine ecosystem function and service delivery, will improve our understanding of anthropogenic impacts on the ocean (McGill et al. 2015).

\subsection{The Distribution of Anthropogenic Stressors in the Marine Environment}

It is clear that the growing human population has put increasing pressure on the world's oceans, leading to varying degrees of decline in marine populations (Kappel 2005; Crain et al. 2009). Anthropogenic stressors are increasing in global intensity and now impact nearly every part of the ocean (Jones et al. 2018). To mitigate these pressures, it is important to understand the main stressors on the marine environment and how they are distributed across the oceans and the marine tree of life.

To do so, we analysed the threats to marine species which are threatened with extinction globally using the IUCN Red List database (IUCN 2017; see Supplementary Material B for full methods). Species threatened with extinction are those that are listed by the IUCN as vulnerable (VU), endangered (EN), or critically endangered (CR) (Box 4.2). We grouped the threats listed by the IUCN into six categories (sensu Young et al. 2016): "habitat destruction and modification," "direct exploitation," "invasive species," "pollution," "climate change," and "other." Based on the frequency by which threatened marine species were affected by different threats, we found the most common threat to be habitat modification and destruction, followed closely by overexploitation (Fig. 4.3a). Pollution, climate change, and invasive species were less frequently observed as threats to threatened marine species (Fig. 4.3a).

The impact of these stressors is pervasive across the marine tree of life (Crain et al. 2009); however, as previously described for extinctions, the average number of threats affecting threatened species varies between taxonomic groups (Fig. 4.3b). Threatened anthozoan species (sea anemones and corals) experience the highest average number of threats (Fig. 4.3b). Coral reefs are impacted by diverse stressors such as overfishing, coastal development, and agricultural runoff (McLeod et al. 2013). Additionally, climate change and ocean acidification are emerging stressors that have caused widespread damage to reefs around the world (Hoegh-Guldberg et al. 2007). Nearly 75\% of the world's coral reefs are affected by these stressors (Burke et al. 2011). Although threatened chondrichthyans (i.e., sharks, rays, and chimeras) are seen to have a relatively lower average number of threats, they are largely threatened by the effects of overexploitation through targeted fisheries and bycatch (Fig. 4.3b). The unique life history characteristics of these cartilaginous fishes (late maturation, slow growth, and low reproduction rates) make them particularly vulnerable to the impact of stressors (Worm et al. 2013).

Several marine areas suffer from high human impact, particularly those where human use of the ocean is the greatest (Halpern et al. 2015). However, the distribution and impact of different anthropogenic stressors vary geographically (Fig. 4.4). Habitat destruction and modification, and overexploitation remain the most important threats to threatened marine species across marine regions; however, their relative contribution to the overall threat level varies considerably between regions (Fig. 4.4). Previous analyses of the cumulative anthropogenic impact on the oceans have shown that the Central and North Atlantic, the Mediterranean, the East Indian, and the Central Pacific are heavily impacted marine regions (Halpern et al. 2015). Our analysis shows that threatened species in the Atlantic and Mediterranean regions are most frequently impacted by overexploitation. Conversely, in the East Indian and Central Pacific regions, habitat modification and destruction constituted the most prevalent threat. The Arctic region is also heavily impacted anthropogenically (Halpern et al. 2015). We found that threatened species in this region are heavily impacted by habitat modification 
a
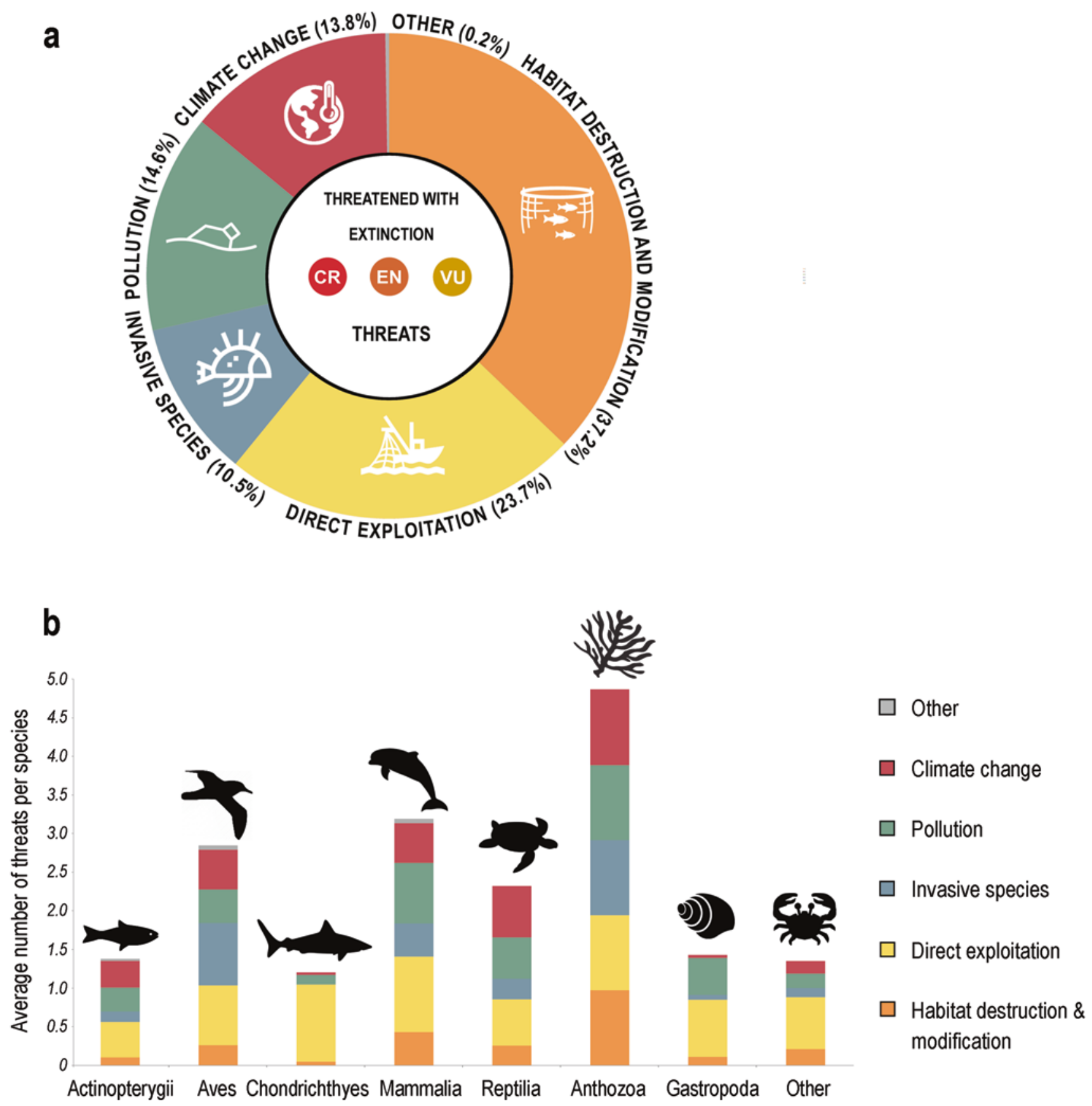

Fig. 4.3 (a) Relative importance of various anthropogenic stressors to species threatened with extinction (critically endangered (CR), endangered (EN) or vulnerable (VU)). (b) Average number of anthropogenic stressors affecting species threatened with extinction for various taxonomic groups. Several taxonomic groups with a low number of species threatened with extinction were pooled under "other" for visualization purposes ("Myxini," "Sarcopterygii," "Polychaeta," "Insecta," "Malacostraca," "Maxillopoda," "Merostomata," "Hydrozoa," and "Holothuroidea"). Colors indicate the percentage contribution of the different anthropogenic stressors. Data extracted from the IUCN Red List database of threats (IUCN 2018). Details on data compilation are provided in the Supplementary Material B and destruction, which corresponds to large-scale habitat alterations driven by changes in sea ice extent (Walsh et al. 2016). Although Antarctica has low overall anthropogenic impacts (Halpern et al. 2015), the most common threat to threatened marine species in this region is overexploitation $(57 \%)$. In summary, these results indicate that anthropogenic threats to threatened marine species differ considerably between marine regions, even if the overall average number of threats may be similar (Fig. 4.4; Halpern et al. 2015). This suggests that reducing anthropogenic impacts on threatened marine species requires targeted approaches specific to each marine region. 


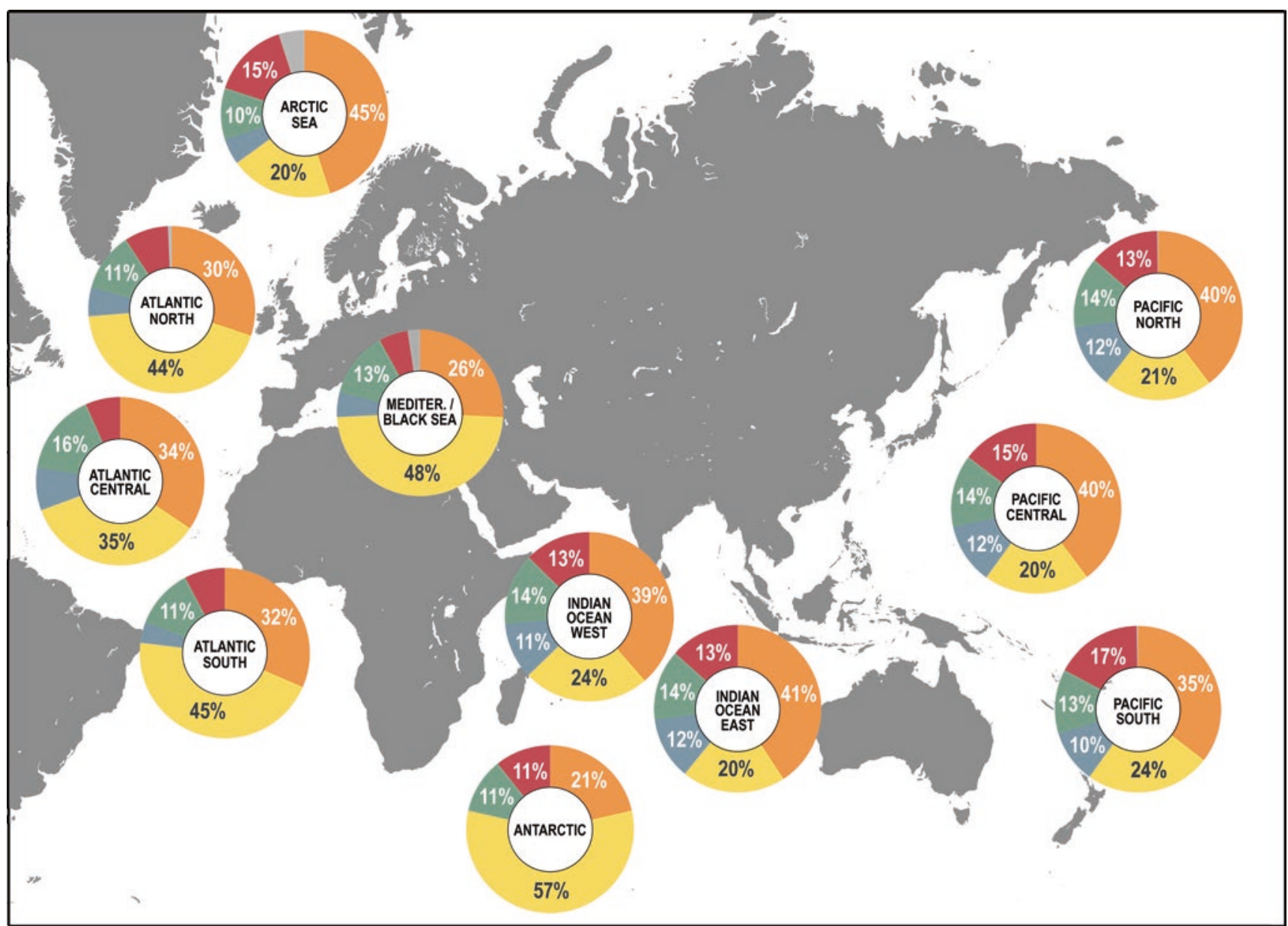

Other

Climate change

Pollution

Invasive species

Overexploitation

Habitat destruction \& modification

Fig. 4.4 The distribution of anthropogenic stressors faced by marine species threatened with extinction in various marine regions of the world. Numbers in the pie charts indicate the percentage contribution of an anthropogenic stressors' impact in a specific marine region.

\subsection{Mitigating Local-Scale Anthropogenic Stressors on Marine Biodiversity}

Conservation interventions are a challenging task due to the large spatial scale and number of stakeholders involved in global threats to marine biodiversity, like climate change, interventions are challenging. The scale of these threats requires international cooperation and considerable changes in current pathways of production and consumption, which could take several decades to achieve, and current progress is slow (Anderson 2012). Nonetheless, emerging evidence from the literature suggests that also the mitigation of localscale threats can aid in the conservation of marine populations. In a recent review, Lotze et al. (2011) found that $10-50 \%$ of surveyed species and ecosystems showed evidence of positive recovery, $95 \%$ of which were due to reduced local-scale threat impacts. Reducing these local-
Percentages under $10 \%$ are not displayed for visualization purposes. Data extracted from IUCN Red List database of threats (IUCN 2018). Details on data compilation are provided in the Supplementary Material B

scale threat levels is, thus, particularly important given the persistent impact of more global-scale threats. Furthermore, while some small-scale threats can be abated by local governments and NGOs, other global threats such as biological invasions and climate change require international collaboration and the cooperation of all stakeholders. Discussing the mitigation of global-scale threats such as invasive species or climate change would be beyond the scope of this review. Thus, the following section will focus on mitigation strategies for local-scale threats such as overexploitation, habitat destruction and modification, and pollution.

Several regulations have been implemented to reduce overexploitation. The main regulatory tools employed in fisheries overharvesting are the use of closed areas, closed seasons, catch limits or bans, effort regulations, gear restrictions, size of fish length regulations, and quotas on certain species (Cooke and Cowx 2006). The use of marine protected areas (MPAs) such as marine reserves (MRs), where 
part of the marine habitat is set aside for population recovery and resource extraction is prohibited, has shown promising results. For instance, across 89 MRs, the density, biomass, and size of organisms, and the diversity of carnivorous fishes, herbivorous fishes, planktivorous fishes, and invertebrates increased in response to reserve establishment (Halpern 2003). Long-term datasets suggest this response can occur rapidly, detecting positive direct effects on target species and indirect effects on non-target species after 5 and 13 years, respectively (Babcock et al. 2010). Successful MPAs often share the key features of being no-take zones (no fishing), well-enforced (to prevent illegal harvesting), older than 10 years, larger than $100 \mathrm{~km}^{2}$, and isolated by deep water or sand (Edgar et al. 2014). Additionally, it is critical to align the planning of the MPA with local societal considerations, as this determines the effectiveness of the MPA (Bennett et al. 2017). Future MPAs should be developed with these key features in mind to maximize their potential. More recently, dynamic modelling approaches encompassing population hindcasts, real-time data, seasonal forecasts, and climate projections have been proposed for dynamic closed zones that would alternate between periods open and closed to fishing (Hazen et al. 2018). Such management strategies based on near real-time data have the potential to adaptively protect both target and bycatch species while supporting fisheries. Non-target species may be under severe threat as their catch data might not be recorded and, thus, rates of decline in these species remain unknown (Lewison et al. 2014). Alterations to fishing gear along with new technological advances reduce the exploitation of non-target species. Increasing mesh size reduces non-target species' capture and prevents the mortality of smaller target species' size classes (Mahon and Hunte 2002). Furthermore, turtle exclusion devices, for example, have proven to be effective in protecting turtles from becoming entrapped in fishing nets (Gearhart et al. 2015). Illuminating gillnets with LED lights has also been shown to reduce turtle (Wang et al. 2013; Ortiz et al. 2016) and seabird bycatch (Mangel et al. 2018).

Reductions in overexploitation have led to rapid recoveries of several historically depleted marine populations, a pattern which is particularly evident for marine mammals (e.g., humpback whales, Northern elephant seals, bowhead whales). Following the ban on commercial whaling in the 1980s, several populations of Southern right whales, Western Arctic bowhead whales, and Northeast Pacific gray whales showed substantial recovery (Baker and Clapham 2004; Alter et al. 2007; Gerber et al. 2007). Similar population increases were observed after the ban on, or reduction of, pinniped hunting for fur, skin, blubber, and ivory (Lotze et al. 2006). Still, populations do not always recover from overexploitation. Many marine fish populations, for instance, have shown limited recovery despite fishing pressure reductions (Hutchings and Reynolds 2004). This might be partly explained by the low population growth rates at small population sizes (Allee effects), which can prevent the recovery of many marine populations (Courchamp et al. 2006). Nonetheless, these examples suggest that marine populations can show resilience to overexploitation and that appropriate management may facilitate population recoveries.

Marine habitats can be destroyed or modified either directly, through activities such as bottom trawling, coral harvesting, clearing of habitat for aquaculture and associated pollution, mining for fossil fuels/metals, and tourism; or indirectly as a consequence of ocean warming, acidification, and sea level rise (Rossi 2013). However, both ultimately lead to the physical destruction/modification or chemical alteration of the habitat which affects its suitability for marine life. The effects of habitat destruction and modification are often permanent or may require intense efforts to restore (Suding et al. 2004; van der Heide et al. 2007). Still, local-scale strategies can be adopted to protect marine habitats. In addition to the aforementioned positive effects on mitigating overexploitation, MRs have been shown to be a useful tool to counteract habitat destruction and modification. For instance, by excluding bottom trawling, MRs can safeguard seafloor habitats and the associated benthic organisms, which are often important ecosystem engineers (Rossi 2013). Furthermore, MRs ban harvesting activities of habitat-building organisms such as sponges, gorgonians, and reef-building corals. In the Bahamas, for example, both the coral cover and size distribution were significantly greater within a marine protected area compared to the surrounding unprotected area (Mumby and Harborne 2010). Additionally, development and resource extraction activities are prohibited within MPAs and MRs, thus, protecting marine habitats directly against destructive activities. Recent increases in habitat protection of coastal areas have contributed to ecosystem recovery in a variety of marine systems such as wetlands, mangroves, seagrass beds, kelp forests, and oyster and coral reefs (Lotze et al. 2011). Currently, approximately $4.8 \%$ of the oceans are within marine protected areas (Marine Conservation Institute 2019), and global goals are set on an expansion to at least $10 \%$ by 2020 under Aichi target 11 of the CBD (CBD, COP Decision $X / 2$ 2010), highlighting the value and broad applicability of MPAs as a tool to protect marine ecosystems.

Nonetheless, MPAs are not a perfect solution to mitigate marine threats at present. An MPA's ability to effectively protect species from overexploitation depends on the enforcement of harvesting regulations, as well as protected area size and connectivity. A review by Wood et al. (2008) found that the median size of MPAs was $4.6 \mathrm{~km}^{2}$, and only half of the world's MPAs were part of a coherent MPA network. This suggests that the majority of MPAs might be insufficiently large to protect species with a large homerange or migrating behavior, such as marine megafauna (Agardy et al. 2011). Additionally, protected areas can only 
effectively negate habitat destruction and modification if their distribution is even and representative for the various habitats at risk, as well as the different biophysical, geographical, and political regions (Hoekstra et al. 2005; Wood et al. 2008). At present, MPAs are heavily biased toward coastal waters. The number of protected areas decreases exponentially with increasing distance from shore, and the pelagic region of the high seas is gravely underrepresented (Wood et al. 2008; Agardy et al. 2011; Thomas et al. 2014). Moreover, the majority of protected areas are situated either in the tropics (between $30^{\circ} \mathrm{N}$ and $30^{\circ} \mathrm{S}$ ) or the upper northern hemisphere $\left(>50^{\circ} \mathrm{N}\right)$, and intermediate $\left(30-50^{\circ}\right)$ and polar $\left(>60^{\circ}\right)$ latitudes are poorly covered.

Marine protected areas can also suffer unintended consequences of MPA establishment. For instance, the establishment of no-take zones might lead to a displacement of resource extraction to the area outside of the reserve. This concentrates the exploitation effort on a smaller area, increasing the pressure on an area which might already be heavily overexploited (Agardy et al. 2011). Additionally, there is increasing evidence the establishment of MPAs might promote the establishment and spread of invasive species (Byers 2005; Klinger et al. 2006; Francour et al. 2010). Finally, even when perfectly designed and managed, MPAs might still fail if the surrounding unprotected area is degraded. For example, the impact of pollution outside of the protected area might negatively affect the marine organisms within the MPA, thus, rendering it ineffective (Agardy et al. 2011). As such, the establishment of MPAs should go hand in hand with mitigation strategies for overexploitation and pollution in the surrounding matrix.

A common source of pollution in the marine environment is the deposition of excess nutrients, a process termed eutrophication. Strategies which are commonly adopted for the mitigation of eutrophication focus on reducing the amount of nitrogen and phosphorous runoff into waterways. Possible solutions to achieve this goal include reducing fertiliser use, more carefully handling manure, increasing soil conservation practices and continuing restoration of wetlands and other riparian buffers (Conley et al. 2009). Reductions in chemical pollution have facilitated population recovery in several marine species (Lotze et al. 2011). For instance, following population declines due to river damming and subsequent pollution, the Atlantic salmon in the St. Croix River (Canada) recovered strongly after efforts to reduce pollution (Lotze and Milewski 2004). In some instances, however, the anthropogenic addition of nutrients has been so great that it has caused ecosystem regime shifts (e.g., Österblom et al. 2007), in which case a reduced nutrient inflow may not be effective at facilitating population recovery.

Marine ecosystems are also commonly disturbed by noise pollution, which has been on the rise since the start of the industrial revolution. Common sources of noise include air and sea transportation, engines from large ocean tankers, icebreakers, marine dredging, construction activities of the oil and gas industry, offshore wind farms, and sound pulses emitted from seismic surveys (Scott 2004 and references therein). Nowacek et al. (2015) urge that an internationally signed agreement by member countries outline a protocol for seismic exploration. This agreement should include restrictions on the time and duration of seismic exploration in biologically important habitats, monitoring acoustic habitat ambient noise levels, developing methods to reduce the acoustic footprint of seismic surveys, creating an intergovernmental science organization, and developing environmental impact assessments. Other management strategies could include speed limits to reduce the noise in decibels emitted by ships, as well as noise reduction construction and design requirements for ships (Richardson et al. 1995, Scott 2004).

Finally, marine debris composed of plastic is one of the world's most pervasive pollution problems affecting our oceans-impacting marine organisms through entanglement and ingestion, use as a transport vector by invasive species, and the absorption of polychlorinated biphenyls (PCBs) from ingested plastics, among others (Derraik 2002; Sheavly and Register 2007). Other than global mitigation measures such as international legislation on garbage disposal at sea (MARPOL 1973), local-scale measures against marine debris pollution include education and conservation advocacy. The Ocean Conservancy organizes an annual International Coastal Cleanup (ICC), which collects information on the amounts and types of marine debris present globally. In 2009, 498,818 volunteers from 108 countries and locations collected 7.4 million pounds of marine debris from over 6,000 sites (Ocean Conservancy 2010). Public awareness campaigns have also been employed as a strategy raise awareness about plastic pollution. An alliance between conservation groups, government agencies, and consumers led a national (USA) ad campaign to help build awareness of boating and fishing groups about the impacts of fishing gear and packaging materials that enter the marine environment (Sheavly and Register 2007).

\subsection{Conclusions}

Overall, the status of marine biodiversity in the Anthropocene is complex. Globally, taxonomic assessments in the marine realm are highly incomplete. Similarly, the rate of assessment of marine species for extinction risk is also slow, at least compared to the terrestrial realm. This lack of assessment may have led to underestimations of the global extinction rate of marine species. Several authors have suggested that current extinction rates in the marine realm are low, but recent evidence suggests that this may be inaccurate due to low rates of assessment of extinction risk. Regardless, the 
loss of marine biodiversity is complex and extinctions or reductions in species richness at any scale do not adequately reflect the changes in marine biodiversity that are occurring. Directional changes in the composition of marine communities are occurring at local scales. These changes are nonrandom, as resident species are replaced by more widespread invaders, which may, over time, reduce diversity in space. The consequence of these changes is lower regional species richness. This, however, is infrequently quantified in the marine realm, and the consequences for ecosystem function and service delivery are poorly known.

In this context, we emphasize recent calls for careful quantification of trends in biodiversity loss at multiple spatial scales and the assessment of the possible effects of various forms of biodiversity loss on ecosystem functioning (e.g., McGill et al. 2015). In particular, population declines are ubiquitous in the marine realm and careful assessment of the effects on ecosystem functions and services are likely critical for understanding human impacts on the marine realm. The anthropogenic threats to marine biodiversity are diverse, cumulative and/or synergistic. Our analysis of the IUCN threats database shows that the main anthropogenic threats vary by both region and taxonomic group. Understanding trends in marine biodiversity thus requires assessing how different taxonomic groups in different regions respond to the various anthropogenic stressors, and how those affect marine biodiversity at different scales of space and time. Furthermore, while some small-scale threats can be abated by local governments and NGOs, other global threats require international collaboration and the cooperation of all stakeholders. This will be a challenge going forward, but will be necessary to fully support marine biodiversity in the Anthropocene.

\section{Appendix}

This article is related to the YOUMARES 9 conference session no. 5: "Species on the brink: navigating conservation in the Anthropocene." The original Call for Abstracts and the abstracts of the presentations within this session can be found in the Appendix "Conference Sessions and Abstracts", Chapter "4 Species on the brink: navigating conservation in the Anthropocene", of this book.

\section{Supplementary Material A: Methods to Estimate Species Diversity}

\section{Early Attempts}

Several early attempts were made to estimate global marine species diversity. Grassle and Maciolek (1992) used data from 233 box-core sediment samples $(30 \times 30 \mathrm{~cm})$ taken at $2 \mathrm{~km}$ depth along a $176 \mathrm{~km}$ transect on the east coast of North America. In these samples, they found $460(58 \%)$ undescribed species of marine macrofauna. Using standard rarefaction curves, they estimated that approximately 100 new species would be discovered per $100 \mathrm{~km}$ of seabed. Extrapolating over the entire ocean, they estimated that 10 million species occurred in marine benthic habitats. Shortly afterwards, May (1994) scaled back Grassle and Maciolek's (1992) estimates considerably by employing a more direct method of estimation. The method used by May (1994) works by increasing the number of globally described species by a factor related to the percentage of undiscovered species found in different sampling campaigns. In Grassle and Maciolek's (1992) samples, 58\% of the species discovered were new. In 1994, there were approximately 200,000 marine macrofaunal species described. Thus, May (1994) estimated that there were likely to be $400,000-500,000$ marine macrofaunal species.

Since these early estimates, several subsequent attempts have been made to estimate marine species diversity (reviewed in Caley et al. 2014). However, since 2010, five estimates of global marine diversity have been published (see Table 4.1). These estimates used variations on one of two methods: extrapolating based on past rates of species discovery or collating expert opinions of undiscovered species.

\section{Extrapolating Based on Past Rates of Species Discovery}

Statistical extrapolation of time-species description accumulation curves from biodiversity databases was used by Costello et al. (2012) and Appeltans et al. (2012) to estimate global marine diversity. Both fit non-homogenous renewable process models to the cumulative number of new species descriptions through time (based on description date) using records on the WoRMS database. These models (Costello and Wilson 2011) decompose time-series data into trend and variation components and allow for variation in the rate of discovery through time. For example, species description rates dropped markedly during the two World Wars (Costello et al. 2012). By fitting these models to the species description time-series, estimates of species that will be discovered at future time points can be made. However, certain analyses have shown that unless the time-species accumulation curves have approached asymptotic levels, estimates are highly uncertain (Bebber et al. 2007).

Higher taxonomic level accumulation curves have recently been used to overcome the asymptotic problem in estimating global species diversity (Mora et al. 2011). Higher taxonomic levels are more completely sampled than lower 
taxonomic levels (i.e., it is unlikely that many more discoveries at the family level will occur). Thus, Mora et al. (2011) used higher taxonomic (phylum to genus) description timeseries from the WoRMS database and estimated their asymptotes. Using regression models, the authors related these higher taxonomic asymptotes to their taxonomic rank (1-5, phylum to genus) and used this model to extrapolate to the species level (taxonomic rank 6).

\section{Estimates Based on Expert Opinion}

The other method that has been applied to estimate global marine species diversity is to collate the estimates of experts of different marine groups. Appeltans et al. (2012) and Costello et al. (2010) used variations of this approach. Appeltans et al. (2012) collated estimates from 270 specialist taxonomists on the total species described, undescribed, and undiscovered for the different marine groups recognized in the WoRMS database. The WoRMS editors that contributed to these estimates are all experts in their taxonomic group and together represent ca. 5\% of the active marine taxonomists. Despite their high level of expertise, all of the experts used markedly different methods to estimate the species number in their respective groups (see Table S2 in Appeltans et al. 2012).

In contrast, the expert opinion approach used by Costello et al. (2010) is a variation on the method used by May (1994). Over 360 scientists representing institutions in Antarctica, Atlantic Europe, Australia, the Baltic Sea, Canada, the Caribbean Sea, China, the Indian Ocean, Japan, the Mediterranean Sea, New Zealand, South Africa, South America, South Korea, and the USA were asked to rate the state of knowledge of different taxonomic groups on a 1-5 scale corresponding to different proportions of described species (e.g., 1 indicates that more than $80 \%$ of species are described). Based on these scores, Costello et al. (2010) estimated that $70-80 \%$ of marine species remain to be described. They then inflated the total described species at the time $(\sim 230,000)$ based on this estimate of uncertainty as per May (1994).

\section{References}

Appeltans W, Ahyong ST, Anderson G et al (2012) The magnitude of global marine species diversity. Curr Biol 22:2189-2202. doi:10.1016/j.cub.2012.09.03

Bebber DP, Marriott FH, Gaston KJ et al (2007) Predicting unknown species numbers using discovery curves. Proc $\mathrm{R}$ Soc Lond B Biol Sci 274:1651-1658. doi:10.1098/ rspb.2007.0464
Caley MJ, Fisher R, Mengersen K (2014) Global species richness estimates have not converged. Trends Ecol Evol 29:187-188. doi:10.1016/j.tree.2014.02.002

Costello MJ, Coll M, Danovaro R et al (2010) A census of marine biodiversity knowledge, resources, and future challenges. PLoS ONE 5:e12110. doi:10.1371/journal. pone.0012110

Costello MJ, Wilson S, Houlding B (2012) Predicting total global species richness using rates of species description and estimates of taxonomic effort. Syst Biol 61:871-883. doi:10.1093/sysbio/syr080

Costello MJ, Wilson SP (2011) Predicting the number of known and unknown species in European seas using rates of description. Glob Ecol Biogeogr 20:319-330. doi:10.1111/j.1466-8238.2010.00603.x

Grassle JF, Maciolek NJ (1992) Deep-sea species richness: regional and local diversity estimates from quantitative bottom samples. Am Nat 139:313-341. doi:10.1086/285329

May RM (1994) Biological diversity: differences between land and sea. Philos Trans Royal Soc B 343:105-111. doi:10.1098/rstb.1994.0014

Mora C, Tittensor DP, Adl S et al (2011) How many species are there on Earth and in the ocean?. PLoS Biol 9:e1001127. doi:10.1371/journal.pbio.1001127

\section{Supplementary Material B: Compilation of Threats Database}

The threats database was compiled using data from the IUCN Red List of Endangered Species online "advanced search" tool (IUCN 2018; https://www.iucnredlist.org/). Marine species were selected, while species living at the interface between marine systems and freshwater or terrestrial systems were omitted from this study. Species listed as "threatened with extinction" (vulnerable - VU, endangered - EN, and critically endangered - CR) were then selected.

The IUCN database offers 12 types of threat categories. However, for visualization, and as the categories related to habitat disturbance are biased towards one type of ecosystem, we followed the approach of Young et al. (2016). The six categories related to disturbance (residential and commercial development, agriculture and aquaculture, energy production and mining, transportation and service corridors, human intrusions and disturbances, and natural system modifications) were pooled under the name "habitat destruction and modification." Additionally, the category "geological events" was pooled with "other options" under the common name "other." The final selection of threats categories was "habitat 
destruction and modification," "direct exploitation," "invasive species," "pollution," "climate change," and "other."

All species in the IUCN Red List database have a listing of threats affecting their populations at present. To assess the relative importance of the various threats to marine species threatened with extinction (Fig. 4.3a), we added the number of times a threat was listed for each marine species threatened with extinction. For the pooled threats (habitat destruction and modification and other), the number of threats per sub-category were added up to get the final number of threats.

We investigated the average number of threats and their relative importance for each marine taxonomic group threatened with extinction (Fig. 4.3b). We included all the taxonomic groups listed by the IUCN database as containing species which are threatened with extinction. In accordance with Fig. 4.1b, groups which contained few species were grouped under "other" for visualization purposes. Additionally, given the frequency by which marine mammals and reptiles are covered in the marine species conservation literature, these taxonomic groups were discussed separately (as opposed to grouping then under "other chordates," as was opted for in Fig. 4.1b). The number of times each threat was listed for a specific taxonomic group was added. For the "other" group, threats for the various subgroups were added up. Unlike the previous method, for the pooled threat categories, the average number of threats was calculated for each taxonomic group, and compared to total number of threats for that taxonomic group to estimate the relative importance of each threat. To calculate the average number of threats per species, we divided the total number threats by the number of species threatened with extinction for that taxonomic group. To construct the figure, the average number of threats per taxonomic group was multiplied by the relative importance of each threat within that group.

Finally, we assessed the relative importance of each threat in the different biogeographic marine regions. The IUCN database offers 19 types of marine regions, however, for visualization, and as certain regions had very similar threat distribution patterns, certain marine biogeographic regions were pooled. The final selection consisted of 11 marine regions: "Arctic sea," "Pacific North" (Pacific Northwest and Pacific Northeast), "Pacific Central" (Pacific Western Central and Pacific Eastern Central), "Pacific South" (Pacific Southwest and Pacific Southeast), "Mediterranean and Black Sea," "Indian Ocean Western," "Indian Ocean Eastern," "Atlantic North" (Atlantic Northwest and Atlantic Northeast), "Atlantic Central" (Atlantic Western Central and Atlantic Eastern Central), "Atlantic South" (Atlantic Southwest and Atlantic Southeast), and "Antarctic" (Pacific Antarctic, Indian Ocean Antarctic and Atlantic Antarctic). Here, we added up the number of times each threat was listed for species threatened with extinction within a certain marine bio- geographic region. For the pooled marine regions, and the pooled threat categories, threat counts were added up.

\section{References}

IUCN (2018) The IUCN Red List of Threatened Species. Version 2018-1. Available: http://www.iucnredlist.org Young HS, McCauley DJ, Galetti M et al (2016) Patterns, causes, and consequences of anthropocene defaunation. Annu Rev Ecol Evol Syst 47:333-358. doi:10.1146/ annurev-ecolsys-112414-054142

\section{References}

Agardy T, di Sciara GN, Christie P (2011) Mind the gap: addressing the shortcomings of marine protected areas through large scale marine spatial planning. Mar Pol 35:226-232. https://doi.org/10.1016/j. marpol.2010.10.006

Airoldi L, Balata D, Beck MW (2008) The gray zone: relationships between habitat loss and marine diversity and their applications in conservation. J Exp Mar Biol Ecol 366:8-15. https://doi. org/10.1016/j.jembe.2008.07.034

Albins MA, Hixon MA (2013) Worst case scenario: potential longterm effects of invasive lionfish (Pterois volitans) on Atlantic and Caribbean coral-reef communities. Environ Biol Fishes 96:11511157. https://doi.org/10.1007/s10641-011-9795-1

Alter ES, Rynes E, Palumbi SR (2007) DNA evidence for historic population size and past ecosystem impacts of gray whales. Proc Natl Acad Sci U S A 104:15162-15167. https://doi.org/10.1073/ pnas.0706056104

Altman S, Whitlatch RB (2007) Effects of small-scale disturbance on invasion success in marine communities. J Exp Mar Biol Ecol 342:15-29. https://doi.org/10.1016/j.jembe.2006.10.011

Anderson K (2012) Climate change going beyond dangerous-Brutal numbers and tenuous hope. Development Dialogue 61:16-40

Anderson SC, Flemming JM, Watson R et al (2010) Serial exploitation of global sea cucumber fisheries. Fish Fish 12:317-339. https://doi. org/10.1111/j.1467-2979.2010.00397.x

Appeltans W, Ahyong ST, Anderson G et al (2012) The magnitude of global marine species diversity. Curr Biol 22:2189-2202. https:// doi.org/10.1016/j.cub.2012.09.03

Babcock RC, Shears NT, Alcala AC et al (2010) Decadal trends in marine reserves reveal differential rates of change in direct and indirect effects. Proc Natl Acad Sci U S A 107:18256-18261. https:// doi.org/10.1073/pnas.0908012107

Baker SC, Clapham PJ (2004) Modelling the past and future of whales and whaling. Trends Ecol Evol 19:365-371. https://doi. org/10.1016/j.tree.2004.05.005

Baker AC, Glynn PW, Riegl B (2008) Climate change and coral reef bleaching: an ecological assessment of long-term impacts, recovery trends and future outlook. Estuar Coast Shelf Sci 80:435-471. https://doi.org/10.1016/j.ecss.2008.09.003

Balata D, Piazzi L, Benedetti-Cecchi L (2007a) Sediment disturbance and loss of beta diversity on subtidal rocky reefs. Ecology 88:24552461. https://doi.org/10.1890/07-0053.1

Balata D, Piazzi L, Cinelli F (2007b) Increase of sedimentation in a subtidal system: effects on the structure and diversity of macroalgal assemblages. J Exp Mar Biol Ecol 351:73-82. https://doi. org/10.1016/j.jembe.2007.06.019 
Balmford A, Gaston KJ (1999) Why biodiversity surveys are good value. Nature 398:204-205. https://doi.org/10.1038/18339

Bando KJ (2006) The roles of competition and disturbance in marine invasion. Biol Invasions 8:755-763. https://doi.org/10.1007/ s10530-005-3543-4

Barange M, Merino G, Blanchard JL et al (2014) Impacts of climate change on marine ecosystem production in societies dependent on fisheries. Nat Clim Chang 4:211. https://doi.org/10.1038/ nclimate2119

Barbier EB, Hacker SD, Kennedy C et al (2011) The value of estuarine and coastal ecosystem services. Ecol Monogr 81:169-193. https:// doi.org/10.1890/10-1510.1

Barnosky AD, Matzke N, Tomiya S et al (2011) Has the Earth's sixth mass extinction already arrived? Nature 471:51-57. https://doi. org/10.1038/nature09678

Baum JK, Worm B (2009) Cascading top-down effects of changing oceanic predator abundances. J Anim Ecol 78:699-714. https://doi. org/10.1111/j.1365-2656.2009.01531.x

Baum JK, Myers RA, Kehler DG et al (2003) Collapse and conservation of shark populations in the Northwest Atlantic. Science 299:389-392. https://doi.org/10.1126/science.1079777

Beck MW, Brumbaugh RD, Airoldi L et al (2011) Oyster reefs at risk and recommendations for conservation, restoration and management BioScience 61:107-116. https://doi.org/10.1525/bio.2011.61.2.5

Bellwood DR, Hughes TP, Folke C et al (2004) Confronting the coral reef crisis. Nature 429:827. https://doi.org/10.1038/ nature 0269117

Bennett NJ, Roth R, Klain SC et al (2017) Conservation social science: understanding \& integrating human dimensions to improve conservation. Biol Cons 205:93-108. https://doi.org/10.1016/j. biocon.2016.10.006

Bini LM, Diniz-Filho JA, Rangel TF et al (2006) Challenging Wallacean and Linnean shortfalls: knowledge gradients and conservation planning in a biodiversity hotspot. Divers Distrib 12:475-482. https:// doi.org/10.1111/j.1366-9516.2006.00286.xs

Bouchet P, Lozouet P, Maestrati P et al (2002) Assessing the magnitude of species richness in tropical marine environments: exceptionally high numbers of molluscs at a New Caledonia site. Biol J Linn Soc 75:421-436. https://doi.org/10.1046/j.1095-8312.2002.00052.x

Brito D (2010) Overcoming the Linnean shortfall: data deficiency and biological survey priorities. Basic Appl Ecol 11:709-713. https:// doi.org/10.1016/j.baae.2010.09.007

Brook BW, Sodhi NS, Bradshaw CJ (2008) Synergies among extinction drivers under global change. Trends Ecol Evol 23:453-460. https:// doi.org/10.1016/j.tree.2008.03.011

Burke L, Reytar K, Spalding M et al (2011) Reefs at risk revisited. World Resources Institute, Washington, DC

Burkepile DE, Hay ME (2008) Herbivore species richness and feeding complementarity affect community structure and function on a coral reef. Proc Natl Acad Sci U S A 105:16201-16206. https://doi. org/10.1073/pnas.0801946105

Butchart SH, Walpole M, Collen B et al (2010) Global biodiversity: indicators of recent declines. Science 328:1164-1168. https://doi. org/10.1126/science. 1187512

Byers JE (2005) Marine reserves enhance abundance but not competitive impacts of a harvested non-indigenous species. Ecol 86:487500. https://doi.org/10.1890/03-0580

Caldeira K, Wickett ME (2003) Oceanography: anthropogenic carbon and ocean pH. Nature 425:365. https://doi.org/10.1038/425365a

Caley MJ, Munday PL (2003) Growth trades off with habitat specialization. Proc R Soc Lond B Biol Sci 270:175-177. https://doi. org/10.1098/rsbl.2003.0040

Cardinale BJ, Duffy JE, Gonzalez A et al (2012) Biodiversity loss and its impact on humanity. Nature 486:59-67
Cardinale BJ, Gonzalez A, Allington GR et al (2018) Is local biodiversity declining or not? A summary of the debate over analysis of species richness time trends. Biol Cons 219:175-183. https://doi. org/10.1016/j.biocon.2017.12.021

Carlton JT, Chapman JW, Geller JB et al (2017) Tsunami-driven rafting: Transoceanic species dispersal and implications for marine biogeography. Science 357:1402-1406. https://doi.org/10.1126/science.aao1498

CBD, COP Decision X/2 (2010) Strategic plan for biodiversity 20112020. Available: http://www.cbd.int/decision/cop/?id=12268

Ceballos G, Ehrlich PR, Barnosky AD et al (2015) Accelerated modern human-induced species losses: entering the sixth mass extinction. Sci Adv 1:e1400253. https://doi.org/10.1126/sciadv.1400253

Claudet J, Fraschetti S (2010) Human-driven impacts on marine habitats: a regional meta-analysis in the Mediterranean Sea. Biol Cons 143:2195-2206. https://doi.org/10.1016/j.biocon.2010.06.004

Clavel J, Julliard R, Devictor V (2011) Worldwide decline of specialist species: toward a global functional homogenization? Front Ecol Environ 9:222-228. https://doi.org/10.1890/080216

Coleman FC, Williams SL (2002) Overexploiting marine ecosystem engineers: potential consequences for biodiversity. Trends Ecol Evol 17:40-44. https://doi.org/10.1016/S0169-5347(01)02330-8

Colles A, Liow LH, Prinzing A (2009) Are specialists at risk under environmental change? Neoecological, paleoecological and phylogenetic approaches. Ecol Lett 12:849-863. https://doi. org/10.1111/j.1461-0248.2009.01336.x

Conley DJ, Paerl HW, Howarth RW et al (2009) Controlling eutrophication: nitrogen and phosphorus. Science 323:1014-1015. https:// doi.org/10.1126/science.1167755

Cooke SJ, Cowx IG (2006) Contrasting recreational and commercial fishing: searching for common issues to promote unified conservation of fisheries resources and aquatic environments. Biol Cons 128:93-108. https://doi.org/10.1016/j.biocon.2005.09.019

Costanza R, d'Arge R, De Groot R et al (1997) The value of the world's ecosystem services and natural capital. Nature 6630:253-260

Costello MJ, Coll M, Danovaro R et al (2010) A census of marine biodiversity knowledge, resources, and future challenges. PLoS ONE 5:e12110. https://doi.org/10.1371/journal.pone.0012110

Costello MJ, Wilson S, Houlding B (2012) Predicting total global species richness using rates of species description and estimates of taxonomic effort. Syst Biol 61:871-883. https://doi.org/10.1093/ sysbio/syr080

Costello MJ, Bouchet P, Boxshall G et al (2013) Global coordination and standardisation in marine biodiversity through the World Register of Marine Species (WoRMS) and related databases. PLoS ONE 8:e51629. https://doi.org/10.1371/journal.pone.0051629

Courchamp F, Angulo E, Rivalan P et al (2006) Rarity value and species extinction: the anthropogenic Allee effect. PLoS Biol 4:e415. https://doi.org/10.1371/journal.pbio.0040415

Crain CM, Kroeker K, Halpern BS (2008) Interactive and cumulative effects of multiple human stressors in marine systems. Ecol Lett 11:1304-1315. https://doi.org/10.1111/j.1461-0248.2008.01253.x

Crain CM, Halpern BS, Beck MW et al (2009) Understanding and managing human threats to the coastal marine environment. Ann NY Acad Sci 1162:39-62. https://doi.org/10.1111/j.1749-6632.2009.04496.x

Creel S, Christianson D (2008) Relationships between direct predation and risk effects. Trends Ecol Evol 23:194-201. https://doi. org/10.1016/J.TREE.2007.12.004

Creel S, Christianson D, Liley S et al (2007) Predation risk affects reproductive physiology and demography of elk. Science 315:960. https://doi.org/10.1126/science.1135918

Crowder LB, Norse E (2008) Essential ecological insights for marine ecosystem-based management and marine spatial planning. Mar Policy 32:772-778. https://doi.org/10.1016/J.MARPOL.2008.03.012 
Crutzen PJ (2002) Geology of mankind. Nature 415:23. https://doi. org/10.1038/415023a

Davies RWD, Cripps SJ, Nickson A et al (2009) Defining and estimating global marine fisheries bycatch. Mar Policy 33:661-672. https:// doi.org/10.1016/j.marpol.2009.01.003

de Vargas C, Audic S, Henry N et al (2015) Eukaryotic plankton diversity in the sunlit ocean. Science 348:1261605. https://doi. org/10.1126/science. 1261605

De Vos JM, Joppa LN, Gittleman JL et al (2015) Estimating the normal background rate of species extinction. Conserv Biol 29:452-462. https://doi.org/10.1111/cobi.12380

Derraik JGB (2002) The pollution of the marine environment by plastic debris: a review. Mar Pollut Bull 44:842-852. https://doi. org/10.1016/S0025-326X(02)00220-5

Dewar WK, Bingham RJ, Iverson RL et al (2006) Does the marine biosphere mix the ocean? J Mar Res 64:541-561. https://doi. org/10.1357/002224006778715720

Dirzo R, Young HS, Galetti M et al (2014) Defaunation in the Anthropocene. Science 345:401-406. https://doi.org/10.1126/ science. 1251817

Doney SC, Ruckelshaus M, Duffy JE et al (2012) Climate change impacts on marine ecosystems. Annu Rev Mar Sci 4:11-37. https:// doi.org/10.1146/annurev-marine-041911-111611

Dornelas M, Gotelli NJ, McGill B et al (2014) Assemblage time series reveal biodiversity change but not systematic loss. Science 344:296-299. https://doi.org/10.1126/science.1248484

Duffy JE (2002) Biodiversity and ecosystem function: the consumer connection. Oikos 99:201-219. https://doi. org/10.1034/j.1600-0706.2002.990201.x

Dulvy NK, Sadovy Y, Reynolds JD (2003) Extinction vulnerability in marine populations. Fish Fish 4:25-64. https://doi. org/10.1046/j.1467-2979.2003.00105.x

Edgar GJ, Stuart-Smith RD, Willis TJ et al (2014) Global conservation outcomes depend on marine protected areas with five key features. Nature 506:216-220

Elahi R, O'Connor MI, Byrnes JE et al (2015) Recent trends in localscale marine biodiversity reflect community structure and human impacts. Curr Biol 25:1938-1943. https://doi.org/10.1016/j. cub.2015.05.030

Estes JA, Tinker MT, Williams TM et al (1998) Killer whale predation on sea otters linking oceanic and nearshore ecosystems. Science 282:473-476. https://doi.org/10.1126/science.282.5388.473

Estes JA, Terborgh J, Brashares JS (2011) Trophic downgrading of planet Earth. Science 333:301-306

Franco-Trecu V, Drago M, Katz H et al (2017) With the noose around the neck: marine debris entangling in otariid species. Environ Pollut 220:985-989. https://doi.org/10.1016/j.envpol.2016.11.057

Francour P, Mangialajo L, Pastor J (2010) Mediterranean marine protected areas and non-indigenous fish spreading. In: Golani D, Appelbaum-Golani B (eds) Fish invasions in the Mediterranean Sea: change and renewal. Pensoft Publishers, Sofia-Moscow, pp 127-144

Frank KT, Petrie B, Choi JS et al (2005) Trophic cascades in a formerly cod-dominated ecosystem. Science 308:1621-1623. https:// doi.org/10.1126/science. 1113075

Friedlander AM, DeMartini EE (2002) Contrast in density, size, and biomass of reef fishes between the northwestern and the main Hawaiian islands: the effects of fishing down apex predators. Mar Ecol Prog Ser 230:253-264. https://doi.org/10.3354/ meps 230253

Futuyama DJ, Moreno G (1988) The evolution of ecological specialization. Annu Rev Ecol Syst 19:207-233. https://doi.org/10.1146/ annurev.es.19.110188.001231

Gamfeldt L, Lefcheck JS, Byrnes JE et al (2015) Marine biodiversity and ecosystem functioning: what's known and what's next? Oikos 124:252-265. https://doi.org/10.1111/oik.01549
García VB, Lucifora LO, Myers RA (2008) The importance of habitat and life history to extinction risk in sharks, skates, rays and chimaeras. Proc R Soc Lond B Biol Sci 275:83-89. https://doi.org/10.1098/ rspb.2007.1295

Gardner TA, Côté IM, Gill JA et al (2003) Long-term region-wide declines in Caribbean corals. Science 301:958-960. https://doi. org/10.1126/science. 1086050

Garrison LP, Link JS (2000) Dietary guild structure of the fish community in the Northeast United States continental shelf ecosystem. Mar Ecol Prog Ser 202:231-240. https://doi.org/10.3354/ meps 202231

Gaston K (1998) Species-range size distributions: products of speciation, extinction and transformation. Philos Trans R Soc B 353:219230. https://doi.org/10.1098/rstb.1998.0204

Gaston KJ (2010) Biodiversity. In: Sodhi NS, Ehrlich PR (eds) Conservation biology for all. Oxford University Press, New York, pp 27-42

Gearhart JL, Hataway BD, Hopkins N et al (2015) 2012 Turtle excluder device (TED) testing and gear evaluations. NOAA Technical Memorandum NMFS-SEFSC-674, 0-29. https://doi.org/10.7289/ V5JW8BTZ

Geburzi JC, McCarthy ML (2018) How do they do it? - Understanding the success of marine invasive species. In: Jungblut S, Liebich V, Bode M (eds) YOUMARES 8 - Oceans Across Boundaries: learning from each other. Springer, Cham, pp 109-124. https://doi. org/10.1007/978-3-319-93284-2_8

Gerber LR, Keller AC, DeMaster DP (2007) Ten thousand and increasing: is the western arctic population of bowhead whale endangered? Biol Conserv 137:577-583. https://doi.org/10.1016/j. biocon.2007.03.024

Grand J, Cummings MP, Rebelo TG et al (2007) Biased data reduce efficiency and effectiveness of conservation reserve networks. Ecol Lett 10:364-374. https://doi.org/10.1111/j.1461-0248.2007.01025.x

Gray JS (2002) Biomagnification in marine systems: the perspective of an ecologist. Mar Pollut Bull 45:46-52. https://doi.org/10.1016/ S0025-326X(01)00323-X

Greene CM, Hall JE, Guilbault KR et al (2010) Improved viability of populations with diverse life-history portfolios. Biol Lett 6:382386. https://doi.org/10.1098/rsbl.2009.0780

Griffiths HJ (2010) Antarctic marine biodiversity-what do we know about the distribution of life in the Southern Ocean? PLoS ONE 5:e11683. https://doi.org/10.1371/journal.pone.0011683

Guinotte JM, Fabry VJ (2008) Ocean acidification and its potential effects on marine ecosystems. Ann N Y Acad Sci 1134:320-342. https://doi.org/10.1196/annals.1439.013

Haberl H, Erb KH, Krausmann F et al (2007) Quantifying and mapping the human appropriation of net primary production in earth's terrestrial ecosystems. Proc Natl Acad Sci U S A 104:12942-12947. https://doi.org/10.1073/pnas.0704243104

Hairston NG, Smith FE, Slobodkin LB (1960) Community structure, population control, and competition. Am Nat 94:421-425. https:// doi.org/10.1086/282146

Halpern BS (2003) The impact of marine reserves: do reserves work and does reserve size matter? Ecol Appl 13:117-137. https://doi. org/10.1890/1051-0761(2003)013[0117:TIOMRD]2.0.CO;2

Halpern BS, Frazier M, Potapenko J et al (2015) Spatial and temporal changes in cumulative human impacts on the world's ocean. Nat Commun 6:7615. https://doi.org/10.1038/ncomms8615

Harley CD, Randall Hughes A, Hultgren KM et al (2006) The impacts of climate change in coastal marine systems. Ecol Lett 9:228-241. https://doi.org/10.1111/j.1461-0248.2005.00871.x

Harnik PG, Lotze HK, Anderson SC et al (2012) Extinctions in ancient and modern seas. Trends Ecol Evol 27:608-617. https://doi. org/10.1016/j.tree.2012.07.010

Harrison PA, Berry PM, Simpson G et al (2014) Linkages between biodiversity attributes and ecosystem services: a systematic 
review. Ecosyst Serv 9:191-203. https://doi.org/10.1016/j. ecoser.2014.05.006

Harvell D, Altizer S, Cattadori IM et al (2009) Climate change and wildlife diseases: when does the host matter the most? Ecology 90:912-920. https://doi.org/10.1890/08-0616.1

Hazen EL, Scales KL, Maxwell SM et al (2018) A dynamic ocean management tool to reduce bycatch and support sustainable fisheries. Sci Adv 4:eaar3001. https://doi.org/10.1126/sciadv.aar3001

Heithaus MR, Frid A, Wirsing AJ et al (2008) Predicting ecological consequences of marine top predator declines. Trends Ecol Evol 23:202-210. https://doi.org/10.1016/J.TREE.2008.01.003

Hilborn R, Branch TA, Ernst B et al (2003) State of the World's Fisheries. Annu Rev Environ Resour 28:359-399. https://doi. org/10.1146/annurev.energy.28.050302.105509

Hillebrand H, Blasius B, Borer ET et al (2018) Biodiversity change is uncoupled from species richness trends: consequences for conservation and monitoring. J Appl Ecol 55:169-184. https://doi. org/10.1111/1365-2664.12959

Hobday AJ, Tegner MK, Haaker PL (2000) Over-exploitation of a broadcast spawning marine invertebrate: decline of the white abalone. Rev Fish Biol Fish 10:493-514. https://doi.org/10.102 3/A:1012274101311

Hoegh-Guldberg O, Mumby PJ, Hooten AJ et al (2007) Coral reefs under rapid climate change and ocean acidification. Science 318:1737-1742. https://doi.org/10.1126/science.1152509

Hoekstra JM, Boucher TM, Ricketts TH et al (2005) Confronting a biome crisis: global disparities of habitat loss and protection. Ecol Lett 8:23-29. https://doi.org/10.1111/j.1461-0248.2004.00686.x

Hulme PE (2009) Trade, transport and trouble: managing invasive species pathways in an era of globalization. J Appl Ecol 46:10-18. https://doi.org/10.1111/j.1365-2664.2008.01600.x

Hutchings JA, Reynolds JD (2004) Marine fish population collapses: consequences for recovery and extinction. BioScience 54:297-309

Hutchings JA, Minto C, Ricard D et al (2010) Trends in the abundance of marine fishes. Can J Fish Aquat Sci 67:1205-1210. https://doi. org/10.1139/F10-081

IPCC (2013) Climate change 2013: the physical science basis. Contribution of working group I to the fifth assessment report of the Intergovernmental Panel on Climate Change. Cambridge University Press, Cambridge. https://doi.org/10.1017/CBO9781107415324

IUCN (2017) The IUCN Red List of Threatened Species. Version $2017-$ 2. Available: http://www.iucnredlist.org

IUCN (2018) The IUCN Red List of Threatened Species. Version 20181. Available: http://www.iucnredlist.org

Jablonski D (1986) Background and mass extinctions: the alternation of macroevolutionary regimes. Science 231:129-133

Jablonski D (1994) Extinctions in the fossil record. Philos Trans Royal Soc B 344:11-17. https://doi.org/10.1098/rstb.1994.0045

Jackson JB, Kirby MX, Berger WH et al (2001) Historical overfishing and the recent collapse of coastal ecosystems. Science 293:629-637

Jennings S, Blanchard JL (2004) Fish abundance with no fishing: predictions based on macroecological theory. J Anim Ecol 73:632-642. https://doi.org/10.1111/j.0021-8790.2004.00839.x

Johannesen E, Ingvaldsen RB, Bogstad B et al (2012) Changes in Barents Sea ecosystem state, 1970-2009: climate fluctuations, human impact, and trophic interactions. ICES J Mar Sci 69:880889. https://doi.org/10.1093/icesjms/fss046

Jones MC, Cheung WW (2014) Multi-model ensemble projections of climate change effects on global marine biodiversity. ICES J Mar Sci 72:741-752. https://doi.org/10.1093/icesjms/fsu172

Jones CG, Lawton JH, Shachak M (1994) Organisms as ecosystem engineers. In: Samson FB, Knopf FL (eds) Ecosystem management. Springer, New York, pp 130-147

Jones KR, Klein CJ, Halpern BS et al (2018) The location and protection status of Earth's diminishing marine wilderness. Curr Biol 28:2506-2512. https://doi.org/10.1016/j.cub.2018.06.010
Kaiser MJ, Collie JS, Hall SJ et al (2002) Modification of marine habitats by trawling activities: prognosis and solutions. Fish Fish 3:114136. https://doi.org/10.1046/j.1467-2979.2002.00079.x

Kappel CV (2005) Losing pieces of the puzzle: threats to marine, estuarine, and diadromous species. Front Ecol Environ 3:275-282. https://doi.org/10.1890/1540-9295(2005)003[0275:LPOTPT]2.0 $\mathrm{CO} ; 2$

Kinlan BP, Gaines SD (2003) Propagule dispersal in marine and terrestrial environments: a community perspective. Ecology 84:20072020. https://doi.org/10.1890/01-0622

Klinger T, Padilla DK, Britton-Simmons K (2006) Two invaders achieve high densities in reserves. Aquat Conserv 16:301-311. https://doi. org/10.1002/aqc.717

Knapp S, Schweiger O, Kraberg A et al (2017) Do drivers of biodiversity change differ in importance across marine and terrestrial systems - Or is it just different research communities' perspectives? Sci Total Environ 574:191-203. https://doi.org/10.1016/j. scitotenv.2016.09.002

Lafferty KD (2004) Fishing for lobsters indirectly increases epidemics in sea urchins. Ecol App 14:1566-1573. https://doi. org/10.1890/03-5088

Lafferty KD, Kuris AM (1993) Mass mortality of abalone Haliotis cracherodii on the California Channel Islands: Tests of epidemiological hypotheses. Mar Ecol Prog Ser 96:239-248

Lanyon JM (2019) Management of megafauna in estuaries and coastal waters: Moreton Bay as a case study. In: Wolanski E, Day JW, Elliot M et al (eds) Coasts and estuaries - the future, 1st edn. Elsevier, Amsterdam, pp 87-101. https://doi.org/10.1016/ B978-0-12-814003-1.00006-X

Laundré JW, Hernández L, Ripple WJ (2010) The landscape of fear: ecological implications of being afraid. Open Ecol J 3:1-7

Lavery TJ, Roudnew B, Gill P et al (2010) Iron defecation by sperm whales stimulates carbon export in the Southern Ocean. Proc R Soc Lond B Biol Sci 277:3527-3531. https://doi.org/10.1098/rspb.2010.0863

Lawler JJ, Aukema JE, Grant JB et al (2006) Conservation science: a 20-year report card. Front Ecol Environ 4:473-480. https://doi. org/10.1890/15409295

Lefcheck JS, Byrnes JE, Isbell F et al (2015) Biodiversity enhances ecosystem multifunctionality across trophic levels and habitats. Nat Commun 6:6936. https://doi.org/10.1038/ncomms7936

Leray M, Knowlton N (2016) Censusing marine eukaryotic diversity in the twenty-first century. Philos Trans Royal Soc B 371:20150331. https://doi.org/10.1098/rstb.2015.0331

Lewison RL, Crowder LB, Wallace BP et al (2014) Global patterns of marine mammal, seabird, and sea turtle bycatch reveal taxa-specific and cumulative megafauna hotspots. Proc Natl Acad Sci U S A 111:5271-5276. https://doi.org/10.1073/pnas.1318960111

Ling SD, Scheibling RE, Rassweiler A et al (2015) Global regime shift dynamics of catastrophic sea urchin overgrazing. Philos Trans Royal Soc B 370:20130269. https://doi.org/10.1098/ rstb.2013.0269

Lockwood JL, Russel GJ, Gittleman JL et al (2002) A metric for analysing taxonomic patterns of extinction risk. Conserv Biol 16:11371142. https://doi.org/10.1046/j.1523-1739.2002.01152.x

Lotze HK, Milewski I (2004) Two centuries of multiple human impacts and successive changes in a North Atlantic food web. Ecol Appl 14:1428-1447. https://doi.org/10.1890/03-5027

Lotze HK, Lenihan HS, Bourque BJ et al (2006) Depletion, degradation, and recovery potential of estuaries and coastal seas. Science 312:1806-1809. https://doi.org/10.1126/science.1128035

Lotze HK, Coll M, Magera AM et al (2011) Recovery of marine animal populations and ecosystems. Trends Ecol Evol 26:595-605. https:// doi.org/10.1016/j.tree.2011.07.008

Magurran AE, Dornelas M, Moyes F et al (2015) Rapid biotic homogenization of marine fish assemblages. Nat Commun 6:8405 
Mahon R, Hunte W (2002) Trap mesh selectivity and the management of reef fishes. Fish Fish 2:356-375. https://doi. org/10.1046/j.1467-2960.2001.00054.x

Mangel JC, Wang J, Alfaro-Shigueto J et al (2018) Illuminating gillnets to save seabirds and the potential for multi-taxa bycatch mitigation. R Soc Open Sci 5:180254. https://doi.org/10.1098/rsos.180254

Marine Conservation Institute (2019) MPAtlas [On-line]. Seattle, WA. Available at: www.mpatlas.org [Accessed 14 March 2019)]

Mark JC, Simon W, Brett H (2012) Predicting total global species richness using rates of species description and estimates of taxonomic effort. Systematic Biology 61 (5):871

MARPOL (1973) International convention for the prevention of pollution from ships: 1973 Convention, 1978 Protocol. Available: http://www.mar.ist.utl.pt/mventura/Projecto-Navios-I/IMOConventions\%20\%28copies\%29/MARPOL.pdf

McCann KS (2000) The diversity-stability debate. Nature 405:228233. https://doi.org/10.1038/35012234

McCauley DJ, Pinsky ML, Palumbi SR et al (2015) Marine defaunation: animal loss in the global ocean. Science 347:1255641. https:// doi.org/10.1126/science.1255641

McGill BJ, Dornelas M, Gotelli NJ et al (2015) Fifteen forms of biodiversity trend in the Anthropocene. Trends Ecol Evol 30:104-113. https://doi.org/10.1016/j.tree.2014.11.006

McKinney ML (1997) Extinction vulnerability and selectivity: combining ecological and paleontological views. Annu Rev Ecol Syst 28:495-516. https://doi.org/10.1146/annurev.ecolsys.28.1.495

McKinney ML, Lockwood JL (1999) Biotic homogenization: a few winners replacing many losers in the next mass extinction. Trends Ecol Evol 14:450-453. https://doi.org/10.1016/S0169-5347(99)01679-1

McLeod E, Anthony KR, Andersson A et al (2013) Preparing to manage coral reefs for ocean acidification: lessons from coral bleaching. Front Ecol Environ 11:20-27. https://doi.org/10.1890/110240

Millennium Ecosystem Assessment (MEA) (2005) Ecosystems and human well-being. Island Press, Washington DC

Mills SL, Soule ME, Doak DF (1993) The keystone-species concept in ecology and conservation. BioScience 43:219-224. https://doi. org/10.2307/1312122

Molnar JL, Gamboa RL, Revenga C et al (2008) Assessing the global threat of invasive species to marine biodiversity. Front Ecol Environ 6:485-492. https://doi.org/10.1890/070064

Mora C, Tittensor DP, Adl S et al (2011) How many species are there on Earth and in the ocean? PLoS Biol 9:e1001127. https://doi. org/10.1371/journal.pbio.1001127

Mumby PJ, Harborne AR (2010) Marine reserves enhance the recovery of corals on Caribbean reefs. PLoS ONE 5:e8657. https://doi. org/10.1371/journal.pone.0008657

Mumby PJ, Hastings A, Edwards HJ (2007) Thresholds and the resilience of Caribbean coral reefs. Nature 450:98-101. https://doi. org/10.1038/nature06252

Myers RA, Worm B (2003) Rapid worldwide depletion of predatory fish communities. Nature 423:280-283. https://doi.org/10.1038/ nature 01610

Myers RA, Worm B (2005) Extinction, survival or recovery of large predatory fishes. Philos Trans R Soc Lond 360:13-20. https://doi. org/10.1098/rstb.2004.1573

Myers RA, Baum JK, Shepherd TD et al (2007) Cascading effects of the loss of apex predatory sharks from a coastal ocean. Science 315:1846-1850. https://doi.org/10.1126/science.1138657

Nowacek DP, Clark CW, Mann D et al (2015) Marine seismic surveys and ocean noise: time for coordinated and prudent planning. Front Ecol Environ 13:378-386. https://doi.org/10.1890/130286

O'Connor S, Ono R, Clarkson C (2011) Pelagic fishing at 42,000 years before the present and the maritime skills of modern humans. Science 334:1117-1121. https://doi.org/10.1126/ science. 1207703
O'Rourke KH, Williamson JG (2002) When did globalization begin? Eur Rev Econ Hist 6:23-50. https://doi.org/10.1017/ S1361491602000023

Ocean Conservancy (2010) Trash travels. From our hands to the sea, around the globe, and through time. Available: https://oceanconservancy.org/wp-content/uploads/2017/04/2010-Ocean-ConservancyICC-Report.pdf

O'Connor MI, Bruno JF, Gaines SD et al (2007) Temperature control of larval dispersal and the implications for marine ecology, evolution, and conservation. Proc Natl Acad Sci U S A 104:1266-1271. https://doi.org/10.1073/pnas.0603422104

Olden JD (2006) Biotic homogenization: a new research agenda for conservation biogeography. J Biogeogr 33:2027-2039. https://doi. org/10.1111/j.1365-2699.2006.01572.x

Olden JD, LeRoy Poff N, Douglas MR et al (2004) Ecological and evolutionary consequences of biotic homogenization. Trends Ecol Evol 19:18-24. https://doi.org/10.1016/j.tree.2003.09.010

Olden JD, Hogan ZS, Vander Zanden MJ (2007) Small fish, big fish, red fish, blue fish: size-biased extinction risk of the world's freshwater and marine fishes. Glob Ecol Biogeogr 16:694-701. https:// doi.org/10.1111/j.1466-8238.2007.00337.x

Orr JC, Fabry VJ, Aumont O et al (2005) Anthropogenic ocean acidification over the twenty-first century and its impact on calcifying organisms. Nature 437:681. https://doi.org/10.1038/ nature 04095

Ortiz N, Mangel JC, Wang J et al (2016) Reducing green turtle bycatch in small-scale fisheries using illuminated gillnets: the cost of saving a sea turtle. Mar Ecol Prog Ser 545:251-259. https://doi. org/10.3354/meps 11610

Österblom H, Hansson S, Larsson U et al (2007) Human-induced trophic cascades and ecological regime shifts in the Baltic Sea. Ecosystems 10:877-889. https://doi.org/10.1007/s10021-007-9069-0

Pacifici M, Foden WB, Visconti P et al (2015) Assessing species vulnerability to climate change. Nat Clim Chang 5:215-224. https://doi. org/10.1038/nclimate2448

Packer C, Holt RD, Hudson PJ et al (2003) Keeping the herds healthy and alert: implications of predator control for infectious disease. Ecol Lett 6:797-802. https://doi. org/10.1046/j.1461-0248.2003.00500.x

Paine RT (1969) A note on trophic complexity and community stability. Am Nat 103:91-93. https://doi.org/10.2307/2459472

Paine RT (1980) Food webs: linkage, interaction strength and community infrastructure. J Anim Ecol 49:666-685. https://doi. org/10.2307/4220

Palumbi SR, Sandifer PA, Allan JD et al (2009) Managing for ocean biodiversity to sustain marine ecosystem services. Front Ecol Environ 7:204-211. https://doi.org/10.1890/070135

Pauly D, Christensen V, Dalsgaard J et al (1998) Fishing down marine food webs. Science 279:860-863. https://doi.org/10.1126/ science. 279.5352 .860

Pershing AJ, Christensen LB, Record NR et al (2010) The impact of whaling on the ocean carbon cycle: why bigger was better. PLoS ONE 5:e12444. https://doi.org/10.1371/journal.pone.0012444

Petchey OL, Gaston KJ (2006) Functional diversity: back to basics and looking forward. Ecol Lett 9:741-758. https://doi. org/10.1111/j.1461-0248.2006.00924.x

Pimm SL, Russell GJ, Gittleman JL et al (1995) The future of biodiversity. Science 269:347-350. https://doi.org/10.1126/ science.269.5222.347

Pimm SL, Jenkins CN, Abell R et al (2014) The biodiversity of species and their rates of extinction, distribution, and protection. Science 344:1246752. https://doi.org/10.1126/science.1246752

Poloczanska ES, Burrows MT, Brown CJ et al (2016) Responses of marine organisms to climate change across oceans. Front Mar Sci 3:1-21. https://doi.org/10.3389/fmars.2016.00062 
Power ME, Tilman D, Estes JA et al (1996) Challenges in the quest for keystones: identifying keystone species is difficult - but essential to understanding how loss of species will affect ecosystems. BioScience 46:609-620. https://doi.org/10.2307/1312990

Purcell SW, Polidoro BA, Hamel JF et al (2014) The cost of being valuable: predictors of extinction risk in marine invertebrates exploited as luxury seafood. Proc R Soc Lond B Biol Sci 281:20133296. https://doi.org/10.1098/rspb.2013.3296

Reynolds JD, Dulvy NK, Goodwin NB et al (2005) Biology of extinction risk in marine fishes. Proc R Soc Lond B Biol Sci 272:23372344. https://doi.org/10.1098/rspb.2005.3281

Richardson WJ, Greene CR, Malme CJ et al (1995) Marine mammals and noise. Academic Press Inc, San Diego

Roberts CM, Hawkins JP (1999) Extinction risk at sea. Trends Ecol Evol 14:241-246. https://doi.org/10.1016/ S0169-5347(98)01584-5

Roman J, McCarthy JJ (2010) The whale pump: marine mammals enhance primary productivity in a coastal basin. PLoS ONE 5:e13255. https://doi.org/10.1371/journal.pone.0013255

Roman J, Estes JA, Morissette L et al (2014) Whales as marine ecosystem engineers. Front Ecol Environ 12:377-385. https://doi. org/10.1890/130220

Rosenzweig ML (1995) Species diversity in space and time. Cambridge University Press, Cambridge

Rosenzweig C, Karoly D, Vicarelli M et al (2008) Attributing physical and biological impacts to anthropogenic climate change. Nature 453:353-357. https://doi.org/10.1038/nature06937

Ross ST (1986) Resource partitioning in fish assemblages: a review of field studies. Copeia:352-388. https://doi org/10.2307/1444996

Rossi S (2013) The destruction of the "animal forests" in the oceans: towards an over-simplification of the benthic ecosystems. Ocean Coast Manage 84:77-85. https://doi.org/10.1016/j. ocecoaman.2013.07.004

Rudkin DM, Young GA, Nowlan GS (2008) The oldest horseshoe crab: a new xiphosurid from late ordovician konservat-lagerstätten deposits, Manitoba Canada. Palaeontol 51:1-9. https://doi org/10.1111/j.1475-4983.2007.00746.x

Sala E, Ballesteros E, Dendrinos P et al (2012) The structure of Mediterranean rocky reef ecosystems across environmental and human gradients, and conservation implications. PLoS ONE 7:e32742. https://doi.org/10.1371/journal.pone.0032742

Sallan L, Galimberti AK (2015) Body-size reduction in vertebrates following the end-Devonian mass extinction. Science 350:812-815. https://doi.org/10.1126/science.aac7373

Sandel B, Arge L, Dalsgaard B et al (2011) The influence of late quaternary climate-change velocity on species endemism. Science 334:660-664. https://doi.org/10.1126/science.1210173

Säterberg T, Sellman S, Ebenman B (2013) High frequency of functional extinctions in ecological networks. Nature 499:468-470. https://doi.org/10.1038/nature 12277

Sax DF, Gaines SD (2003) Species diversity: from global decreases to local increases. Trends Ecol Evol 18:561-566. https://doi. org/10.1016/S0169-5347(03)00224-6

Scavia D, Field JC, Boesch DF et al (2002) Climate change impacts on US coastal and marine ecosystems. Estuaries 25:149-164. https:// doi.org/10.1007/BF02691304

Scheffer M, Carpenter S, Foley JA (2001) Catastrophic shifts in ecosystems. Nature 413:591-596

Schindler DE, Armstrong JB, Reed TE (2015) The portfolio concept in ecology and evolution. Front Ecol Environ 13:257-263. https://doi. org/10.1890/140275

Scott KN (2004) International regulation of undersea noise. Int Comp Law Q 53:287-324

Secretariat of the Convention on Biological Diversity and the Scientific and Technical Advisory Panel - GEF (2012) Impacts of marine debris on biodiversity: current status and potential solutions. CBD Technical Series 67:1-61

Severtsov AS, Shubkina AV (2015) Predator-prey interaction between individuals: 1 . The role of predators in natural selection. Biol Bull 42:633-642. https://doi.org/10.1134/S1062359015070080

Sguotti C, Cormon X (2018) Regime shifts - a global challenge for the sustainable use of our marine resources. In: Jungblut S, Liebich V, Bode M (eds) YOUMARES 8 - Oceans Across Boundaries: learning from each other. Springer, Cham, pp 155-166. https://doi. org/10.1007/978-3-319-93284-2_11

Sheavly SB, Register KM (2007) Marine debris and plastics: environmental concerns, sources, impacts and solutions. J Polym Environ 15:301-305. https://doi.org/10.1007/s10924-007-0074-3

Shimada T, Limpus C, Jones R et al (2017) Aligning habitat use with management zoning to reduce vessel strike of sea turtles. Ocean Coast Manag 142:163-172. https://doi.org/10.1016/j. ocecoaman.2017.03.028

Smith FA, Lyons SK, Ernest SM et al (2003) Body mass of late quaternary mammals. Ecol 84:3403. https://doi.org/10.1890/02-9003

Sorte CJ, Williams SL, Carlton JT (2010) Marine range shifts and species introductions: comparative spread rates and community impacts. Global Ecol Biogeogr 19:303-316. https://doi. org/10.1111/j.1466-8238.2009.00519.x

Steffen W, Broadgate W, Deutsch L et al (2015) The trajectory of the Anthropocene: the great acceleration. Anthropocene Rev 2:81-98. https://doi.org/10.1177/2053019614564785

Steneck RS, Graham MH, Bourque BJ et al (2002) Kelp forest ecosystems: biodiversity, stability, resilience and future. Environ Conserv 29:436-459. https://doi.org/10.1017/S0376892902000322

Steneck RS, Leland A, McNaught DC et al (2013) Ecosystem flips, locks, and feedbacks: the lasting effects of fisheries on Maine's kelp forest ecosystem. Bull Mar Sci 89:31-55. https://doi.org/10.5343/ bms. 2011.1148

Suding KN, Gross KL, Houseman GR (2004) Alternative states and positive feedbacks in restoration ecology. Trends Ecol Evol 19:4653. https://doi.org/10.1016/j.tree.2003.10.005

Thomas HL, Macsharry B, Morgan L et al (2014) Evaluating official marine protected area coverage for Aichi Target 11: appraising the data and methods that define our progress. Aquat Conserv 24:8-23. https://doi.org/10.1002/aqc.2511

Thrush SF, Gray JS, Hewitt JE et al (2006) Predicting the effects of habitat homogenization on marine biodiversity. Ecol Appl 16:16361642. https://doi.org/10.1890/1051-0761(2006)016[1636:PTEOHH ]2.0.CO;2

United Nations General Assembly (2015) Transforming our world: the 2030 agenda for sustainable development. Available: http://www.un.org/ga/search/view_doc.asp?symbol=A/ RES/70/1\&Lang $=\mathrm{E}$

Valiela I, Bowen JL, York JK (2001) Mangrove forests: One of the world's threatened major tropical environments: at least $35 \%$ of the area of mangrove forests has been lost in the past two decades, losses that exceed those for tropical rain forests and coral reefs, two other well-known threatened environments. BioScience 51:807815. https://doi.org/10.1641/0006-3568(2001)051[0807:MFOOTW ]2.0.CO;2

van der Heide T, van Nes EH, Geerling GW et al (2007) Positive feedbacks in seagrass ecosystems: implications for success in conservation and restoration. Ecosystems 10:1311-1322. https://doi. org/10.1007/s10021-007-9099-7

Villarrubia-Gómez P, Cornell SE, Fabres J (2018) Marine plastic pollution as a planetary boundary threat-the drifting piece in the sustainability puzzle. Mar Policy 96:213-220. https://doi.org/10.1016/j. marpol.2017.11.035

Walsh JE, Fetterer F, Scott Stewart J et al (2016) A database for depicting Arctic sea ice variations back to 1850 . Geogr Rev 107:89-107. https://doi.org/10.1111/j.1931-0846.2016.12195.x 
Wang J, Barkan J, Fisler S et al (2013) Developing ultraviolet illumination of gillnets as a method to reduce sea turtle bycatch. Biol Lett 9:20130383. https://doi.org/10.1098/rsbl.2013.0383

Waycott M, Duarte CM, Carruthers TJ et al (2009) Accelerating loss of seagrasses across the globe threatens coastal ecosystems. Proc Natl Acad Sci U S A 106:12377-12381. https://doi.org/10.1073/ pnas.0905620106

Webb TJ, Mindel BL (2015) Global patterns of extinction risk in marine and non-marine systems. Curr Biol 25:506-511. https://doi. org/10.1016/j.cub.2014.12.023

Webb TJ, Berghe EV, O'Dor R (2010) Biodiversity's big wet secret: the global distribution of marine biological records reveals chronic under-exploration of the deep pelagic ocean. PLoS ONE 5:e10223. https://doi.org/10.1371/journal.pone.0010223

Wilcox C, Van Sebille E, Hardesty BD (2015) Threat of plastic pollution to seabirds is global, pervasive and increasing. Prod Natl Acad Sci U S A 112:11899-11904. https://doi.org/10.1073/ pnas. 1502108112

Wilmers CC, Estes JA, Edwards M et al (2012) Do trophic cascades affect the storage and flux of atmospheric carbon? An analysis of sea otters and kelp forests. Front Ecol Environ 10:409-415. https:// doi.org/10.1890/110176

Winfree R, Fox JW, Williams NM et al (2015) Abundance of common species, not species richness, drives delivery of a real-world ecosystem service. Ecol Lett 18:626-635. https://doi.org/10.1111/ ele. 12424

Wood LJ, Fish L, Laughren J et al (2008) Assessing progress towards global marine protection targets: shortfalls in information and action. Oryx 42:340-351. https://doi.org/10.1017/ s003060530800046x

Worm B, Tittensor DP (2011) Range contraction in large pelagic predators. Proc Natl Acad Sci U S A 108:11942-11947. https://doi. org/10.1073/pnas.1102353108

Worm B, Barbier EB, Beaumont $\mathrm{N}$ et al (2006) Impacts of biodiversity loss on ocean ecosystem services. Science 314:787-790. https://doi. org/10.1126/science.1132294

Worm B, Davis B, Kettemer L et al (2013) Global catches, exploitation rates, and rebuilding options for sharks. Mar Policy 40:194-204. https://doi.org/10.1016/j.marpol.2012.12.034

WoRMS Editorial Board (2018) World Register of Marine Species. http://www.marinespecies.org. Accessed 15 April 2018. doi: $10.14284 / 170$

WWF (2015) Living Blue Planet Report. Species, habitats and human well-being. WWF, Gland

Young HS, McCauley DJ, Galetti M et al (2016) Patterns, causes, and consequences of anthropocene defaunation. Annu Rev Ecol Evol Syst 47:333-358. https://doi.org/10.1146/ annurev-ecolsys-112414-054142

Open Access This chapter is licensed under the terms of the Creative Commons Attribution 4.0 International License (http://creativecommons. org/licenses/by/4.0/), which permits use, sharing, adaptation, distribution and reproduction in any medium or format, as long as you give appropriate credit to the original author(s) and the source, provide a link to the Creative Commons license and indicate if changes were made.

The images or other third party material in this chapter are included in the chapter's Creative Commons license, unless indicated otherwise in a credit line to the material. If material is not included in the chapter's Creative Commons license and your intended use is not permitted by statutory regulation or exceeds the permitted use, you will need to obtain permission directly from the copyright holder. 